\title{
(6) OPEN ACCESS \\ Critical research gaps and recommendations to inform research prioritisation for more effective prevention and improved outcomes in colorectal cancer
}

\author{
Mark Lawler, ${ }^{1}$ Deborah Alsina, ${ }^{2}$ Richard A Adams, ${ }^{3}$ Annie S Anderson, ${ }_{1}^{4}$ Gina Brown, ${ }^{5}$ \\ Nicola S Fearnhead, ${ }_{1}^{6}$ Stephen W Fenwick, ${ }^{7}$ Stephen P Halloran, ${ }^{8}$ Daniel Hochhauser, ${ }^{9}$ \\ Mark A Hull, ${ }^{10}$ Viktor H Koelzer, ${ }^{11}$ Angus G K McNair, ${ }^{12}$ Kevin J Monahan, ${ }^{13}$ \\ Inke Näthke, ${ }^{14}$ Christine Norton, ${ }^{15}$ Marco R Novelli, ${ }^{16}$ Robert J C Steele, ${ }^{4}$ \\ Anne L Thomas, ${ }^{17}$ Lisa M Wilde, ${ }^{2,18}$ Richard H Wilson, ${ }^{1}$ Ian Tomlinson, ${ }^{19}$ on behalf of \\ the Bowel Cancer UK Critical Research Gaps in Colorectal Cancer Initiative
}

- Additional material is published online only. To view please visit the journal online (http://dx.doi.org/10.1136/ gutjnl-2017-315333).

For numbered affiliations see end of article.

\section{Correspondence to} Professor Mark Lawler, Centre for Cancer Research and Cell Biology Queen's University Belfast, University Road, Belfast BT7 1NN, UK; mark.lawler@ qub.ac.uk

Received 22 September 2017 Revised 24 October 2017 Accepted 25 October 2017

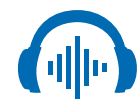

Listen to Podcast www.goo.gl/k5BXPb
Check for updates

To cite: Lawler $M$ Alsina D, Adams RA, et al. Gut 2018;67:179-193.

\section{ABSTRACT}

Objective Colorectal cancer (CRC) leads to significant morbidity/mortality worldwide. Defining critical research gaps $(R G)$, their prioritisation and resolution, could improve patient outcomes.

Design RG analysis was conducted by a multidisciplinary panel of patients, clinicians and researchers $(n=71)$. Eight working groups (WG) were constituted: discovery science; risk; prevention; early diagnosis and screening; pathology; curative treatment; stage IV disease; and living with and beyond CRC. A series of discussions led to development of draft papers by each WG, which were evaluated by a 20-strong patient panel. A final list of RGs and research recommendations (RR) was endorsed by all participants.

Results Fifteen critical RGs are summarised below: $R G 1$ : Lack of realistic models that recapitulate tumour/tumour micro/macroenvironment; $R G 2$ : Insufficient evidence on precise contributions of genetic/environmental/lifestyle factors to $C R C$ risk; $R G 3$ : Pressing need for prevention trials; $R G 4$ : Lack of integration of different prevention approaches; $R G 5$ : Lack of optimal strategies for CRC screening; $R G 6$ : Lack of effective triage systems for invasive investigations; $R G 7$ : Imprecise pathological assessment of CRC; $R G 8$ : Lack of qualified personnel in genomics, data sciences and digital pathology; RG9: Inadequate assessment/communication of risk, benefit and uncertainty of treatment choices; $R G 10$ : Need for novel technologies/interventions to improve curative outcomes; RG 11: Lack of approaches that recognise molecular interplay between metastasising tumours and their microenvironment; $R G 12$ : Lack of reliable biomarkers to guide stage IV treatment; $R G 13$ : Need to increase understanding of health related quality of life (HRQOL) and promote residual symptom resolution; $R G 14$ : Lack of coordination of CRC research/funding; $R G 15$ : Lack of effective communication between relevant stakeholders.

Conclusion Prioritising research activity and funding could have a significant impact on reducing CRC disease burden over the next 5 years.

\section{INTRODUCTION}

The global burden of colorectal cancer (CRC) is rising, with 2.2 million predicted new cases (and 1.1 million deaths) by $2030 .{ }^{1}$ In the UK, $>41000$ new cases were diagnosed in 2014 , and $\sim 16000$ people died of the disease. ${ }^{2}$ Estimates of the global economic burden of CRC approach $\$ 100$ billion; $^{3}$ in the USA, medical expenditure alone is predicted to rise to $>\$ 20$ billion by $2020 .{ }^{4}$ In the UK, total economic costs of CRC exceeded $£ 1.6$ billion in 2009. ${ }^{5}$

In 2014, the US National Cancer Institute (NCI) spent \$223 million for CRC research, placing it fourth behind breast cancer ( $\$ 530$ million), lung cancer (\$254 million) and leukaemia (\$237 million). ${ }^{6}$ Cancer Research UK (CRUK) figures indicated that its annual expense specifically on CRC research in 2016-2017 was $£ 35$ million, second behind lung cancer research ( $£ 43$ million) and ahead of breast cancer research ( $£ 33$ million). ${ }^{7}$ Recognising the need to identify current and emerging CRC research gaps (RG) to inform research policy and prioritisation, the UK charity Bowel Cancer UK (BCUK), aided by the UK National Cancer Research Institute (NCRI) Colorectal Cancer Clinical Studies Group and The Association of Coloproctology of Great Britain and Ireland (ACPGBI), drew together health professionals, scientists and those affected by CRC to identify those research priorities which, if addressed, would make the greatest impact on lessening global CRC burden.

\section{METHODOLOGY}

During 2015-2016, BCUK recruited an all-encompassing panel of $71 \mathrm{CRC}$ healthcare professionals (HCP), scientists and individuals affected by CRC to participate in the BCUK Critical Research Gaps in Colorectal Cancer Initiative. The process is outlined in figure 1 and reflects previous approaches to identifying RGs in other diseases. ${ }^{8}$ A detailed description of the process/methodology is provided in online supplementary appendix 1 . 

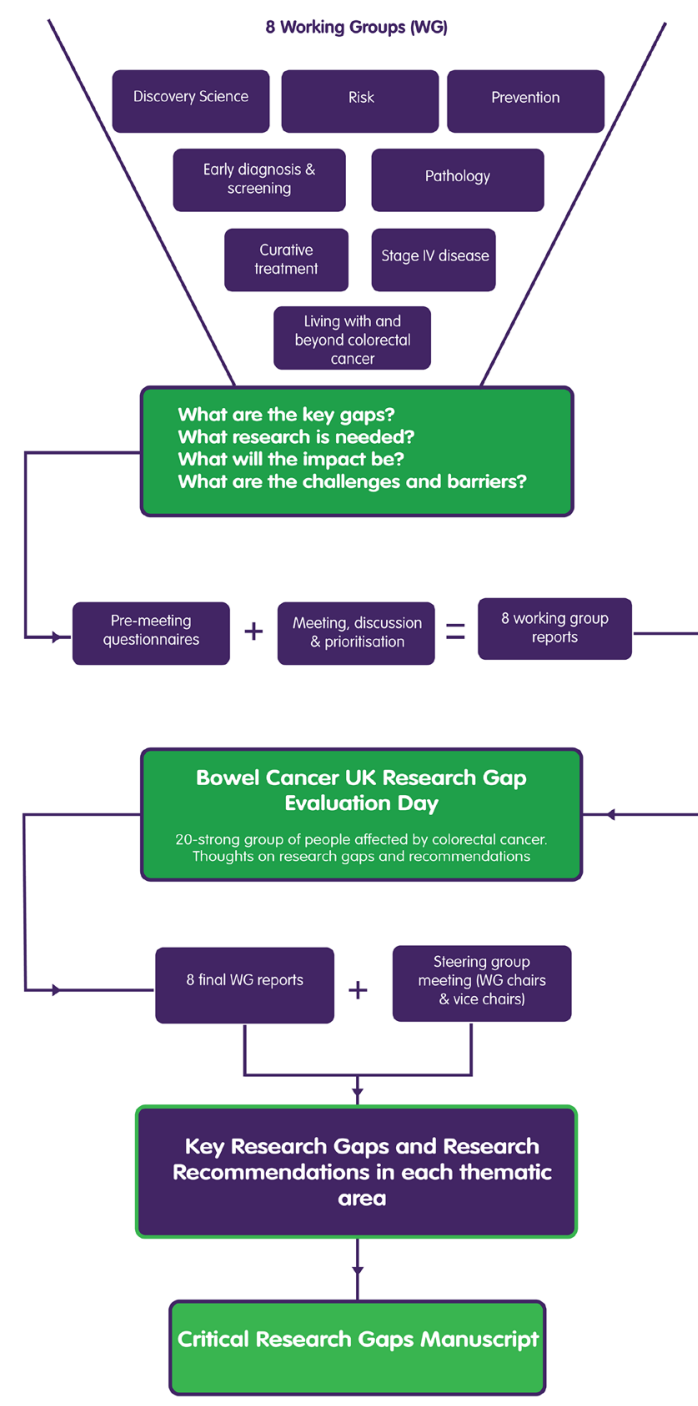

Figure 1 Bowel Cancer UK Critical Research Gaps in Colorectal Cancer Initiative process.

\section{RESULTS}

Fifteen critical RGs were identified through the process indicated in figure 1 and described in detail in online supplementary appendix 1 . These RGs are summarised in table 1 , and the evidence base for the RGs, together with accompanying research recommendations (RR), is detailed below in relevant thematic areas.

\section{EVIDENCE BASE FOR RESEARCH GAPSS AND RECOMMENDATIONS \\ Discovery science \\ Current status}

Interrogating colorectal biology has revealed important clues to key events driving CRC growth, including aberrant Wnt signalling and specific defects in DNA mismatch repair (MMR). ${ }^{9-13}$ Gene expression profiling efforts are identifying specific CRC molecular subtypes, although their clinical relevance requires further elucidation. ${ }^{13-18}$

Many key areas require further in-depth study. While intracancer molecular diversity has been highlighted, ${ }^{16-18}$ we are only starting to understand the greater complexity associated with CRC evolution and metastasis. ${ }^{19}$ Transforming growth factor-beta/bone morphogenic protein signalling appears important for CRC growth and metastasis, ${ }^{20}$ but there is scant knowledge of the key proteins involved. Other pathways, for example, Hippo, and STING, are intriguing players in CRC biology, but are currently of uncertain relevance. ${ }^{2122}$ The tumour micro/macroenvironment, including the microbiome, is largely unexplored. Crucially, the dearth of reliable CRC model systems is compromising both relevant fundamental research and development of novel therapies.

Research Gap (RG1): A need for realistic in silico, in vitro and in vivo models that more precisely recapitulate the tumour and its micro/macroenvironment, to enable comprehensive dissection of the relevant mechanisms governing the transition from normal colorectum to the different malignant stages of the disease.

\section{Model systems for CRC research}

While cell line models have informed our overall understanding of CRC biology, the recognition that they may not represent a specific tumour within its particular genetic context and microenvironment milieu has prompted researchers to develop more realistic models that recapitulate different premalignant/malignant stages of CRC. Genetically engineered mouse models, ${ }^{23}$ for example, the $A p c^{\mathrm{Min} /+}$ mouse ${ }^{24}$ have allowed interrogation of particular disease biology, while the advent of patient-derived xenografts has underpinned development of animal models representing different stages of human CRC. ${ }^{25}$ Organoids have allowed the 3D structure/microenvironment of the CRC tumour to be recreated and manipulated. ${ }^{26}$ However, as our molecular knowledge of CRC expands, ${ }^{13-17}$ we require models that map to distinct disease subtypes, and others that address issues such as CRC evolution, intratumoural heterogeneity and treatment resistance.

Research Recommendation 1.1 (RR1.1): Develop and share appropriate model systems that mimic different premalignant/malignant stages of colorectal cancer (CRC), to ensure discovery research questions are addressed in the relevant genetic/clinical context.

Investigating CRC signalling pathways and their tractability Given that pathogenic adenomatous polyposis coli (APC) mutations are rare outside CRC, performing a comprehensive, cell type-specific molecular analysis of the normal and APC-mutant colorectal crypt would improve understanding of the critical pathways/processes underpinning malignant colorectal epithelium development. A concerted Wnt pathway investigation programme in normal cells, benign tumours, and primary and metastatic CRC (mCRC) tissue is warranted. Challenges include development of appropriate quantitative readouts of signalling pathways, and novel model systems, perhaps including large animal models with greater resemblance to humans. Precise elucidation of specific malignant cellular processes could underpin identification of novel targets, both for prevention and treatment.

RR1.2: Comprehensively interrogate the normal and APC-mutant colorectal crypt to reveal differences that may be exploitable for CRC prevention/control.

\section{The CRC micro/macroenvironment}

We need to consider the role of non-neoplastic cells, particularly stromal cells/fibroblasts and immune infiltrates as important arbiters of CRC processes and treatment responses, to better understand the tumour microenvironment and how it is controlled by the cancer itself. ${ }^{16-18}$ Organoid models, or appropriate animal 
Table 1 Critical RGs in colorectal cancer

\begin{tabular}{|c|c|}
\hline Research area & Critical RGs \\
\hline Discovery science & $\begin{array}{l}\text { RG1: A need for realistic in silico, in vitro and in vivo models that more precisely recapitulate the tumour and its micro/macroenvironment, to enable } \\
\text { comprehensive dissection of the relevant mechanisms governing the transition from normal colorectum to the different malignant stages of the } \\
\text { disease. }\end{array}$ \\
\hline Prevention & $\begin{array}{l}\text { RG3: A need for intervention trials of preventive strategies addressing 'dose', timing, target group and acceptability, as well as mechanism of action. } \\
\text { RG4: Lack of interdisciplinary collaboration is undermining evaluation of real-life preventative interventions in CRC. }\end{array}$ \\
\hline $\begin{array}{l}\text { Pathology: diagnosis - } \\
\text { prognosis - prediction }\end{array}$ & $\begin{array}{l}\text { RG7: Imprecise pathological assessment of CRC is an unmet challenge. } \\
\text { RG8: Lack of qualified personnel to apply state-of-the-art knowledge in genomics, big data science and digital pathology. }\end{array}$ \\
\hline Curative treatment & $\begin{array}{l}\text { RG9: Inadequate assessment and communication of risk, benefit and uncertainty of treatment choices where cure is possible. } \\
\text { RG10: A need for novel technologies/interventions that have the potential to improve curative outcomes. }\end{array}$ \\
\hline Stage IV disease & $\begin{array}{l}\text { RG11: Lack of approaches that take cognisance of the molecular interplay between the metastasising tumour and its microenvironment and help } \\
\text { guide evolution of innovative treatments that deliver improved health outcomes for the stage IV patient. } \\
\text { RG12: Lack of reliable prognostic and predictive biomarkers to help guide stage IV patient pathways. }\end{array}$ \\
\hline \multirow[t]{2}{*}{$\begin{array}{l}\text { Overarching RGs that need } \\
\text { to be addressed }\end{array}$} & $\begin{array}{l}\text { RG14: Lack of coordination of CRC research and its funding, leading to fragmented efforts to elucidate the biology of the disease and translate this } \\
\text { knowledge into new preventative agents, screening tools, diagnostics and therapeutics. }\end{array}$ \\
\hline & $\begin{array}{l}\text { RG15: Lack of effective communication strategies between healthcare professionals, patients with CRC/survivors, those at elevated risk of developing } \\
\text { CRC, and the general public and varying levels of awareness of key risk factors, prevention options and benefits/risks associated with different } \\
\text { treatment options. }\end{array}$ \\
\hline
\end{tabular}

CRC, colorectal cancer; $R G$, research gap.

models encompassing both neoplastic clones and realistic microenvironments are paramount. Development of in silico systems biology platforms that capitalise on these rich data sources will allow modelling and deciphering of the complex interplay between CRC tumour cells and their microenvironment.

Macroenvironmental effects from gut microbes have been implicated in CRC development in experimental animal models, but their relevance in humans is less clear. Recent evidence published in this journal suggests that altered mucosal microbiota are present throughout the colorectum, ${ }^{27}$ that they have a role in regulating the host immune-inflammatory response, and may have prognostic relevance for patients with CRC. A deeper understanding of the gut microbiome in CRC will also facilitate its therapeutic manipulation for improved outcomes in both preventative and treatment settings.

RR1.3: Better understand the molecular/cellular interplay between the CRC tumour and its microenvironment.

RR1.4: Determine the role of the gut microbiome and how it can be exploited to improve CRC disease outcomes.

\section{Risk}

Current status

Identifying individuals at increased risk of CRC allows introduction of appropriate screening/surveillance approaches, leading to earlier cancer diagnosis and underpinning improved survival. However, there is currently an incomplete picture of the absolute risk attributable to inherited, environmental or lifestyle factors for CRC. Understanding global risk will underpin stratified interventions tailored to individual patients for disease modification and precision medicine interventions. ${ }^{28}$

Known Mendelian conditions account for a relatively small proportion of inherited risk, with the remainder thought to be due to lower penetrance risk factors, including common/ rare genetic variants. ${ }^{29}$ Approximately 40 common, low penetrance CRC risk alleles have been identified. ${ }^{29}$ Estimations from whole-exome sequencing (WES) studies suggest that higher penetrance rare variants may additionally account for $16 \%$ of hereditary risk. ${ }^{30}$ However, much of the 'missing heritability' remains unidentified. Additionally, the interaction between the microbiome, epigenetics and heritable risk factors remains poorly characterised. ${ }^{31}$

A better understanding of environmental/lifestyle risk factors is also required. While associations with diet, ${ }^{32-34}$ comorbidities including diabetes ${ }^{35}$ and aspirin/non-steroidal anti-inflammatory drug use, ${ }^{36}$ have been identified, the interplay between these risk factors is complex. A greater understanding would permit targeted public health approaches to increase risk factor awareness in the general population, leading to reduced CRC incidence. ${ }^{37}$

RG2: Insufficient evidence on the precise contributions of genetic, environmental and lifestyle factors, and in particular how they interact together to influence the risk of developing CRC.

\section{Genetic risk factors for CRC}

There is incomplete elucidation of CRC heritable risk factors, especially of polygenic risk (ie, where the contribution of multiple genes must be enumerated/quantified). Collaborative initiatives such as GECCO (Genetics and Epidemiology of Colorectal Cancer Consortium) ${ }^{38}$ and GAME-ON (Genetic Associations and Mechanisms in Oncology Consortium) ${ }^{39}$ have significantly contributed to identification of risk-susceptibility loci. $^{40-42}$ However, additional gene discovery initiatives are required, with increased concentration on evaluation of genetic risk in a broader diversity of populations/ethnic groups. ${ }^{43} 44$ International data sharing collaboratives will be required, particularly to evaluate significance of rare genetic variants. Developing a gene panel for common CRC risk variants, mirroring a similar recently applied approach in breast cancer, ${ }^{45}$ may allow more precise delineation of CRC risk. 
RR2.1: Conduct comprehensive genetic susceptibility studies, supported by enabling data sharing platforms, in appropriately diverse human populations to maximise identification of genetic risks factors that have general applicability, or are relevant to specific ethnic populations.

\section{Environmental/lifestyle contributions to CRC risk}

There are significant environmental/lifestyle contributors to enhanced CRC risk. Increasingly, we require precise data-analytic tools to evaluate, assign and quantify gene-gene, ${ }^{46}$ gene-environment and gene-lifestyle risk. ${ }^{478}$ Recent studies have linked high-quality diets (assessed by diet quality indices) with low CRC risk in a multiethnic cohort, ${ }^{49}$ while a genome-wide dietgene interaction analysis indicated a novel association between processed meat consumption, a particular genetic variant and increased CRC risk. ${ }^{48}$ Studies have also investigated interactions between gene variants, smoking/alcohol consumption and risk of developing CRC. ${ }^{50}$ Ensuring the robustness of data-analytic methodologies and applying them to high-quality large data sets will help confirm current hypotheses, and identify novel naturenurture interactions for further modelling and testing in diverse populations and cohorts, to determine the universality of their ability to predict increased/reduced risk.

RR2.2: Develop robust data analytical tools that define and quantify the precise interplay between genetic and environmental/lifestyle factors to attributable CRC risk.

\section{Population-based assessment of CRC risk}

International collaboration is continually cataloguing potential independent lifestyle risk indicators in population studies. ${ }^{34}$ However, we need prospective high-quality pan-population studies of CRC risk factors, with complete ascertainment, accurate longitudinal clinical and pathological data, and supporting blood/tissue samples. Collection of high-quality treatment response and toxicity data should also be mandated to help identify risk factors for relapse or treatment-related side effects. A national registry approach to managing risk may be the best way to identify an unbiased population set of high-risk patients. This should be linked to clinical networks, including national approaches to surveillance and screening, enabling development of enhanced prevention and surveillance programmes for highrisk patients, ${ }^{51}$ and reallocation of valuable resources for those at low risk. ${ }^{52}$

RR2.3: Design and implement prospective high-quality pan-population studies of risk factors for CRC, with robust clinical/pathological data, supporting blood and tissue samples, to inform a population-based assessment of risk.

\section{Prevention}

Current status

Despite widespread awareness that efforts to avoid CRC development are critical, ${ }^{53}$ prevention research is under-represented in the CRC research portfolio. The UK NCRI funding in 2015 for all cancers was $£ 498$ million, but only $3 \%$ was spent on prevention. ${ }^{54}$ The gap in CRC prevention research is particularly notable in high-risk populations, such as patients with Lynch syndrome. ${ }^{55}$ The preventability estimate (World Cancer Research Fund) indicates that $\sim 45 \%$ of CRCs are accounted for by lifestyle factors (dietary factors, obesity, lack of physical activity and alcohol consumption ${ }^{56}$ ). Dietary factors (low dietary fibre intake, high red/processed meat intake) are considered the main lifestyle area of concern. ${ }^{56}$ An evolving understanding of the gut microbiome and diet-microbial interactions has highlighted the potential for modulation of the diet-microbiome-metabolome axis for cancer prevention. ${ }^{57}$

The global impact of obesity on cancer is significant, contributing to $\sim 10 \%$ of the overall cancer burden in North America, Europe and the Middle East. ${ }^{58}$ This is reflected in a significant association between increasing body mass index (BMI) and CRC development. ${ }^{59}$ The International Agency for Research on Cancer recently convened a working group (WG) to assess body fatness and cancer risk. For CRC, their findings confirmed the association between increased BMI and CRC risk and indicated that a significant body of preclinical data supported a preventative effect of calorific restriction; ${ }^{60}$ this should be actively pursued. Increased physical activity also has an important role in CRC prevention strategies. ${ }^{61}$

There is compelling evidence that chemopreventive interventions such as aspirin ${ }^{5562} 63$ in high-risk patients can be effective, prompting the US Preventive Services Task Force to recommended its use in primary CRC prevention. ${ }^{64}$ However, complications, including GI bleeding, need to be considered, although the harm-versus-benefit ratio is frequently exaggerated. ${ }^{65}$ Additionally, a recent study has indicated a lack of awareness of aspirin's chemopreventive effects by $>50 \%$ of primary care physicians surveyed, ${ }^{66}$ particularly for high-risk populations (eg, Lynch syndrome carriers), highlighting the need for appropriate education/guidance strategies. Many intervention trials (of diet, physical activity or chemoprevention) occur in the postdiagnosis setting-we need to ensure more CRC preventive trials which target specific high-risk populations with robust endpoints are conducted prior to CRC onset.

RG3: A need for intervention trials of preventive strategies addressing 'dose', timing, target group and acceptability, as well as mechanism of action.

RG4: Lack of interdisciplinary collaboration is undermining evaluation of real-life preventative interventions in CRC.

\section{Integrating dietary, lifestyle and chemopreventive interventions}

There is an increasing need to reflect how interventions can be delivered in 'real life' (eg, combining screening, lifestyle interventions and chemoprevention), going beyond traditional discipline boundaries when designing efficacy and, particularly, effectiveness studies. New research models and transdisciplinary paradigms must be established in CRC prevention, perhaps in an approach analogous to NCI's Transdisciplinary Research on Energetics and Cancer Initiative, ${ }^{67}$ which brought together expertise in behaviour, biostatistics, computer science, discovery science, endocrinology, engineering, epidemiology, genetics, health economics, medicine, nutrition and physical activity. We need multidisciplinary approaches to help define optimal ways to implement lifestyle change programmes. Another example is the microbiome, ${ }^{68}$ where our increased understanding of gut microbiota $^{69}$ and their manipulation is highlighting how diet/ nutrient/physical activity-based interventional approaches can help prime the microbiome as a preventative agent.

RR3.1: Encourage transdisciplinary, multimodal approaches to CRC prevention, through cross-community collaboration.

The need for long-term studies

There is a dearth of studies which enable observational (and other) evidence to be tested robustly in long-term studies. Challenges include recruitment (due to incorrect perceptions about 
disease prevention, particularly lifestyle interventions, and lack of HCP support), protocol implementation and adherence, and lack of appropriate endpoints. We need longer term analysis of robust interventions demonstrating feasibility and acceptability with promising indicative outcomes, ${ }^{70}$ which can then be tested in full-scale trials of relevant duration, with clinically relevant outcomes in at-risk patients.

RR3.2: Ensure future delivery of high-quality robust long-term studies that identify the appropriate level of intervention including dose, duration, timing, feasibility and acceptability as well as clinically relevant outcome(s)

\section{Ensuring coordination of intervention trials and research into barriers to uptake}

Intervention trials and research into barriers to uptake of research findings and clinical impact must occur concurrently. We also need to break down current regulatory and funding hurdles to timely and cost-effective prevention research, particularly for interventions employing off-licence drugs, undesignated drugs (eg, food supplements), or requiring human resource, for example, a counsellor/dietitian/trained volunteer/physical activity trainer. Stronger public involvement in evaluating optimal ways to promote more effective diet and lifestyle interventions, including the need to optimise teachable moments ${ }^{71}$ should be encouraged.

RR4.1: Coordinate interventional trial activity to ensure maximum impact of precise and effective prevention strategies across the population.

\section{Defining mechanism of action of selected interventions}

A better understanding of mechanism(s) of action of prevention interventions is needed in order to define the most effective intervention, its timing and 'dose', as well as identifying individuals most likely to benefit. Intervention trials and observational cohorts could usefully include blood/tissue biobanks as key enablers of mechanistic research. Specific research calls for multimodal intervention studies should be developed with emphasis on effectiveness (including non-cancer secondary endpoints) and health economic outcomes.

RR4.2: Promote studies that help elucidate mechanism of action of prevention interventions.

RR4.3: Develop precise individual risk stratification approaches to ensure prevention interventions are employed most effectively.

\section{Early diagnosis and screening}

\section{Current status}

Although colonoscopy is widely employed for screening asymptomatic individuals in the USA, most countries have adopted a single biennial faecal immunochemical test (FIT) for blood in the stool for programmatic screening. ${ }^{72}$ As a population screening tool, colonoscopy is expensive, associated with low uptake and is potentially hazardous. FIT is easy to deliver and affordable in cost-limited or colonoscopy-limited settings, by simply adjusting the FIT sensitivity thresholds. High sensitivity from low FIT thresholds decreases specificity and test precision, leading to higher false-positive rates, increased patient anxiety and pressure on colonoscopy services. ${ }^{7374}$

Population screening using a single flexible sigmoidoscopy (FS) has proven efficacy with reduced CRC incidence and mortality. ${ }^{75}$ FS at age 55 has been adopted by the English Bowel Screening Programme prior to guaiac-based Faecal Occult Blood
Test at age 60. Limited FS resource and poor pathology yield in the age group chosen for the English programme may challenge the prospective clinical benefits observed in randomised clinical trials (RCT).

Early diagnosis by prompt recognition and reporting of symptoms by the public has been advocated, but to date has only succeeded in increasing rates of referral for investigation (usually colonoscopy), with no impact on rates of diagnosis of early disease. ${ }^{7677}$ These initiatives have created increased pressure on diagnostic services; the need for effective triage of symptomatic patients is urgent. There is interest in the use of 'low threshold FIT' as an aid to decision-making. ${ }^{78}$ The National Institute for Health and Care Excellence has recently issued guidance recommending highly sensitive FIT testing in patients with low-risk colorectal symptoms. ${ }^{79}$

Colonoscopy in population screening is being examined worldwide, but mortality data will not be available for $10-15$ years. ${ }^{80}$ CT colonography is another screening modality, but pilot RCTs have yet to provide mortality data. ${ }^{81} 82$ Aside from expediting adoption of FS at an appropriate age(s), future developments in population screening include refining use of FIT by cost analysis of different thresholds, introduction of risk-adjusted screening with conventional or machine learning techniques and development of new markers.

RG5: Lack of an optimal strategy for screening for CRC.

RG6: Lack of an effective triage system for symptomatic patients that can determine who will benefit most from invasive investigation.

\section{Risk adjustment}

The threshold of faecal haemoglobin concentration that triggers a colonoscopy can be adjusted to increase sensitivity. ${ }^{73}$ While modelling studies have assessed the cost-effectiveness of changes to the FIT threshold, RCTs would supplement these studies.

RR5.1: Embed research RCTs in FIT-based screening programmes to explore the optimal FIT threshold and/or the role of flexible sigmoidoscopy, incorporating risk adjustment algorithms.

Another approach to FIT-based risk assessment is to incorporate age, gender ${ }^{83} 84$ and participant's screening history (eg, adherence to biennial screening, previous FS or colonoscopy, and so on, and other risk markers such as primary care blood results, ${ }^{85}$ BMI or smoking status). An alternative or additional approach is to vary the screening interval, depending on FIT concentration or concentration trends or more comprehensive risk scores which incorporate age, gender and specific symptoms.

\section{New technologies}

Several technologies including analysis of DNA from faecal samples ${ }^{86}$ and use of peripheral blood biomarkers such as methylated Septin $9^{87}$ have not yet proven to be as clinically sensitive as FIT in population screening. Current developments include the detection of volatile metabolites in breath, ${ }^{88}$ use of liquid biopsies, ${ }^{89}$ the potential role of changes in the microbiome ${ }^{90}$ and colon capsule endoscopy. ${ }^{91}$ These emerging technologies could be combined with morpho-molecular parameters if not for screening, then for risk stratification in early-stage disease and predicting disease recurrence. ${ }^{92} 93$

RR6.1: Establish accurate risk-based assessment of symptomatic patients, incorporating FIT and promising novel technologies. RR6.2: Develop and trial sensitive and specific tests that could be employed in both screening and symptomatic services. 


\section{Pathology: diagnosis-prognosis-prediction}

\section{Current status}

The present gold standard to assign patients with CRC to prognostic groups is the TNM (tumour, node, metastases) classification. ${ }^{94} 95$ This anatomic staging approach frequently clusters patients with biologically different diseases and allows only approximate estimates of survival outcomes. Increasing the accuracy and reproducibility of morphological prognostic factors is therefore a major challenge for pathologists. ${ }^{96-98}$

Ongoing research promotes incorporation of an increasing number of molecular biomarkers into the CRC specimen reporting. ${ }^{99}$ Well-established elements include immunohistochemistry testing of MMR protein expression, analysis of microsatellite instability and MLH1 promoter hypermethylation. Clinical next-generation sequencing can underpin the fast, reliable, broadly applicable and cost-effective detection of mutations for prognostication and prediction of response to targeted agents. ${ }^{100-102}$ Understanding the patient's genetic context is also important for prognosis, treatment response and toxicity. ${ }^{103} 104$ Clinical success of immune-checkpoint inhibitor therapy in hypermutated CRC is driving the search for novel biomarkers to help stratify immunotherapy-based approaches. ${ }^{105}$ Advances in gene expression profiling ${ }^{106-108}$ have culminated in a consensus molecular subtype classification, ${ }^{13}$ but its clinical value is currently unclear.

Overall, there is a critical need to revitalise CRC biomarker research, which has previously been limited by inconsistent methodologies and lack of reproducibility. Digital pathology, translational bioinformatics and machine learning must become critical components of modern pathology,${ }^{109}$ integrating rapidly expanding clinical and laboratory data sets to underpin algorithm development for risk prediction/disease stratification. This creates a presently unmet demand for large numbers of highly qualified personnel in the pathology sector.

RG7: Imprecise pathological assessment of CRC is an unmet challenge.

\section{Risk stratification in early-stage disease}

RGs are evident in the morphology-based risk stratification of colorectal precursor lesions and in clinical surveillance of patients with IBD. Although pathologists are mostly effective at diagnosing high-grade lesions, morphological categories are broad and interobserver reproducibility is limited. ${ }^{110}$ Translation of discovery research findings on the molecular pathogenesis of IBD-associated neoplasia will help improve utility and cost-effectiveness of screening approaches at the population level.

In stage I disease, most patients are cured by endoscopic polyp removal. However, up to $20 \%$ of cases may have occult nodal micrometastasis at time of resection. ${ }^{111112}$ Stratification through assessment of additional histomorphological risk factors is heterogeneously reported and prone to variable reproducibility. ${ }^{9899} 113$ Methodological standardisation and integration of biological data is needed to improve risk prediction in early-stage disease.

RR7.1: Precisely define the morpho-molecular taxonomy of precursor lesions and early-stage disease to help inform risk stratification in CRC.

\section{Predicting disease recurrence and treatment response}

Better approaches to predict recurrence, therapy response and toxicity are required to guide personalised treatment of patients with CRC. Reliable identification of high-risk stage II patients is a presently unmet challenge. ${ }^{114-117}$ Most patients with stage III disease will receive standard chemotherapy or radiotherapy. ${ }^{118}$ However, up to $70 \%$ will not relapse following potentially curative resection, derive no benefit from chemotherapy and suffer toxic side effects. ${ }^{119}$ In stage IV disease, there is a need for accurate stratification for surgical treatment and early detection of evolving drug resistance. Further integration of genomic, ${ }^{102}$ immune $^{120}$ and transcriptomic approaches ${ }^{13-17}$ 106-108 into pathologic tumour staging is a critical enabler for personalised treatment of patients with CRC.

RR7.2: Develop new standardised molecularly informed multiparameter algorithms to permit improved prediction of disease recurrence and therapy response.

\section{Developing robust molecular signatures for precision pathology} analysis

Molecular taxonomy studies have highlighted the important contribution of the stroma to CRC, and its association with poor prognosis disease. ${ }^{16} 17$ However, intratumoural heterogeneity, due to variations in stromal content, ${ }^{15-18}$ can compromise clinical application of molecular profiling. The recent discovery of a CRC intrinsic signature ${ }^{14}$ may have more robust prognostic/ predictive relevance, ${ }^{15}$ and should be considered for inclusion in molecular pathology workflows. A key enabling technology is the improved analysis of formalin-fixed paraffin-embedded tissues (and alternative non-formalin-based fixatives), given the logistical challenges with use of fresh-frozen tissue.

RR7.3: Use our evolving understanding of the CRC tumour and its microenvironment to underpin standardised approaches for pathology specimen analysis.

\section{Growing the talent pool and skilling the pathology workforce}

Genomic medicine is given limited space in medical curricula and pathology training. Know-how in digital image analysis, bioinformatics and machine learning is currently lacking, compromising development and application of next-generation diagnostic tools. Pathologists are thus at risk of losing their methodological competence to lead, evaluate and guide biomarker testing in personalised medicine and biomedical research.

RG8: Lack of qualified personnel to apply state-of-the-art knowledge in genomics, big data science and digital pathology.

The UK government's life sciences strategy lists molecular diagnostics, digital pathology and artificial intelligence as key strategic areas for further development. ${ }^{121}$ Structured educational programmes in genomics/bioinformatics should be offered to complement existing training. Exemplary efforts to promote genomic pathology education have been made (eg, Health Education England's Medical Genomics Programme (UK) ${ }^{122}$; Training Residents in Genomics Working Group (USA)). ${ }^{123}$ A network approach in conjunction with national/international pathological societies is warranted to advance learning for the present and future workforce. Funded programmes should be established to encourage collaboration of histopathologists with molecular geneticists, bioinformaticians and physical scientists to establish optimal methodologies of data accumulation/integration, thus retooling and empowering the emerging molecular pathology generation.

RR8.1: Embed interdisciplinary education/training within undergraduate/postgraduate and continuing professional education curricula to ensure recruitment, retention and upskilling of 
qualified personnel to deliver modern pathology to the CRC community.

\section{Curative treatment}

Current status

Recent technological advances have improved the quality of curative therapies: the advent, evaluation and widespread adoption of laparoscopic colorectal surgery, for example, have improved short-term recovery at no expense to survival. ${ }^{124} 125$ However, there are significant regional variations in the delivery of certain innovations because of a lack of definitive research studies. ${ }^{126}$

Cure is becoming increasingly feasible, but effective patient-centred care requires consideration of broader treatment effects. Patients with advanced disease may have access to novel therapies with only limited survival benefits but which cause major morbidity. Similarly, patients with very 'curable' disease may want to explore treatment options with reduced chance of cure but minimal impact on health-related quality of life (HRQOL). ${ }^{127}$ Current research continues to investigate treatments that minimise toxicity (SCOT and IDEA trials) ${ }^{128} 129$ or amplify survival for patients undergoing established treatments (eg, ADD-ASPIRIN, CHALLENGE and FOxTROT trials). ${ }^{130-132}$

\begin{abstract}
RG9: Inadequate assessment and communication of risk, benefit and uncertainty of treatment choices where cure is possible. RG10: A need for novel technologies/interventions that have the potential to improve curative outcomes.
\end{abstract}

\section{Informing shared decision-making}

Great advances have been made in understanding, implementing and optimising patient-centred care; ${ }^{133}$ however, further work is needed to address the specific issues in new and evolving CRC therapies. Appropriate research, answering key questions that inform shared decision-making, must be conducted.

It is now accepted, for example, that definitive radiotherapy and organ preservation may be a viable alternative to major resectional surgery. ${ }^{134135}$ Communicating the balance between patient experience and maximising survival in rectal cancer is extremely relevant. A non-surgical approach may lead to better HRQOL but with a reduced chance of cure, while a major surgery has greater immediate risks, but may have a higher chance of cure.

RR9.1: Develop an appropriate evidence base to inform shared decision-making for potentially curative therapies for patients.

\section{Establishing optimum peritherapeutic interventions}

Critical to shared decision-making is anaesthetic risk assessment ${ }^{136}$ but currently there remain limitations in tools that give us a valid risk assessment for more frail patients and/or those with significant comorbidities. ${ }^{137}$ Mitigating risk or optimally reducing its impact is a vital component in improving outcomes. We need to improve pre/post/perioperative management to enhance patient experience (both short term and long term) and survival after 'curative therapies'.

RR10.1: Establish optimum peritherapeutic interventions to improve curative outcomes.

Optimising health-preserving benefit in metastatic/recurrent disease We have continued to push the boundaries of curative interventions in CRC. ${ }^{138}$ Selecting an individual for potentially more aggressive approaches when the disease has spread beyond the confines of the bowel has become commonplace, but each time we extend these boundaries, further evaluation to fill our knowledge gap is required. Specifically, questions arise such as: 'How should we select patients for novel curative therapeutic interventions for oligometastatic disease?', 'What is the role of ablative technologies for cure in metastatic disease?' and 'What is the evidence for highly aggressive surgical intervention for recurrent/locally advanced disease?'

RR10.2: Optimise curative approaches for metastatic or recurrent disease that balance patients' expectations with treatment efficacy and health-preserving benefit.

\section{Biomarkers for optimal treatment selection}

Broad technological advances have been made in CRC therapy including surgery, radiotherapy and molecular-based treatment. ${ }^{139-141}$ These advances may impact upon existing therapeutic options, for example, by optimising the use of chemotherapies in the adjuvant setting to avoid excessive toxicities, or by underpinning newer biomarker-driven treatment selection. This aims to move beyond the standard of care to a more individualised approach.

RR10.3: Develop biomarkers that define the optimal curative therapeutic strategy for an individual or group, preventing overtreatment and improving treatment selection.

\section{New methodologies}

Methods to ensure optimal evaluation of new surgical and radiotherapy-related devices and procedures ${ }^{142} 143$ are needed to demonstrate appropriately robust clinical and cost-effective outcomes. Such methods have been promoted by the IDEAL (Idea, Development, Exploration, Assessment, Long-term follow-up) collaboration, ${ }^{144}$ but further methodological development is needed, particularly in early phase studies. This will promote consistency in standard therapeutic pathway development, ensuring that the best therapies are more widely used, based on compelling evidence at an earlier stage. It is critically important to define the interventions to be tested, but equally important are methodologies for their evaluation, providing the evidence base to encourage their integration into clinical practice to enhance curative outcomes.

RR10.4: Develop research methodologies to optimally evaluate new curative approaches.

\section{Stage IV disease \\ Current status}

Around $20 \%$ of patients presenting with CRC have metastatic disease (mCRC) at time of diagnosis. ${ }^{145}$ A further 20\%-25\% will develop mCRC during follow-up after initial curative intent treatment of their primary tumour. Recently, there has been an expansion in the range of modalities available for treating stage IV CRC. More aggressive approaches to resection of mCRC (particularly major liver resection), combined with ablative technologies and loco-regional treatments, are allowing potentially curative options to be offered to more patients. For chemotherapy, the single agent ( 5 -fluorouracil) available 20 years ago has multiplied into 13 available drugs in 2016. ${ }^{146}$ Despite these incremental advances in patient treatment, disease cure remains unattainable for many.

Genomic technologies have given valuable insights into CRC heterogeneity, leading to identification of distinctive molecular subtypes. ${ }^{13-15}$ Knowledge of the associated clinical ramifications of these subtypes should help optimise treatment strategies. Recent advances in immunotherapy have resulted 
in significant clinical benefit in non-small cell lung cancer and melanoma. ${ }^{147-149}$ We need to translate these successes into new treatment approaches in CRC, beyond the benefit already seen with immune-checkpoint inhibition in the $\sim 5 \%$ of patients with metastatic disease whose tumours have deficient DNA MMR. ${ }^{150}$

RG11: Lack of approaches that take cognisance of the molecular interplay between the metastasising tumour and its microenvironment and help guide evolution of innovative treatments that deliver improved health outcomes for the stage IV patient.

\section{Multimodality treatment in stage IV disease}

There have been major developments in surgical resection of both primary and metastatic diseases, with advanced techniques permitting radical resection. ${ }^{151}$ However, fundamental questions remain unanswered such as whether primary tumour resection in the presence of synchronous inoperable metastatic disease affects the natural history of the disease. It is now possible to perform radical peritonectomies and major pelvic exenterations for primary and recurrent disease, ${ }^{152} 153$ but significant variations in practice from preoperative imaging through to clinical intervention remain. Understanding which patients to select for which procedure is challenging, and outcome data, including increasingly relevant long-term patient-reported outcome measures (PROMs) are not robust.

Minimally invasive surgical techniques are being evaluated in mCRC management, ${ }^{154}$ and in the UK a trial is open comparing resection and percutaneous ablation in operable liver metastases. ${ }^{155}$ Disappointingly, the initial promise observed in trials investigating radioembolisation in patients with inoperable liver metastases has not translated into improved overall survival. ${ }^{143}$ Currently, only patients with low-burden, circumscribed metastases are potentially curable. Consensus guidelines on the sequence, setting (eg, supraregional centres for certain aspects of care) and timing of multimodality treatment, including systemic therapy to downsize inoperable disease, would translate into more patients being cured, including those with multisite metastatic disease. Even in non-curable disease, the role of multimodality therapy combining downstaging systemic therapies, resection and ablation of the majority of multiorgan $\mathrm{mCRC}$, may allow prolonged survival with good HRQOL and freedom from symptoms. This concept of 'optimal debulking', based on clinical practice in ovarian cancer, is now being investigated in CRC, in clinical trials such as ORCHESTRA, ${ }^{156}$ and should be explored more widely.

RR11.1: Develop evidence-based approaches utilising multimodality treatment for patients with stage IV CRC to maximise the utility of cutting-edge technologies to improve outcomes.

RG12: Lack of reliable prognostic and predictive biomarkers to help guide stage IV patient pathways.

\section{Stratification of patients}

The lack of widely accepted prognostic and predictive biomarkers results in limited consensus to guide stage IV patient pathways. For example, how should we adopt WES/whole-genome sequencing into our standard of care and how do we interpret and transmit large-scale multiomics data for clinical decision-making? Transcriptomic analysis is starting to yield clinically relevant results which can help inform molecular stratification of patients with CRC to improve outcomes. Trials such as FOCUS-4, a multistage multiarm approach in CRC, may provide the appropriate model going forward. ${ }^{157}$ An important consideration is the increasing age of the population, as more frail patients with complex medical needs are diagnosed. Accurately recognising and understanding which aspects of patient frailty are reversible (and potentially be amenable to prehabilitation) remains challenging.

RR12.1: Establish robust prognostic and predictive biomarkers to stratify patients to ensure every patient receives 'bespoke' treatment, relevant to their particular disease course.

\section{Understanding the microenvironment to help develop innovative} treatments

Colon carcinogenesis occurs within an inflammatory microenvironment where gut bacteria provide constant immune stimulation. Therefore, many immunosuppressive processes have been developed in colonic epithelium to prevent these bacteria-induced inflammatory triggers. ${ }^{158}$ Interplay between the gut microbiome, inflammation and carcinogenesis is complex but is critical to understand to improve CRC treatment.

CRC stem cells play a significant role in intratumoural heterogeneity. ${ }^{159}$ As a dynamic population of cells, they respond to genetic and epigenetic factors along with microenvironmental signals to influence key processes such as metastatic potential and chemotherapy resistance. CRC cells can thus continuously adapt to their environment, highlighting the difficulty of developing suitable models to target cancer stem cells by directed therapies.

To date, despite significant efforts, immune-mediated approaches in CRC have had limited success. High gene mutational load ${ }^{160}$ and the presence of DNA MMR deficiency and DNA polymerase E proofreading mutations ${ }^{150} 161$ correlate with improved outcomes to immune-checkpoint inhibitors. Immunoscore is a scoring system based on quantifying the number of cytotoxic and memory $\mathrm{T}$ cells infiltrating the core and leading edge of the tumour. ${ }^{97} 162$ Using this approach may allow identification of a prognostic biomarker of responsiveness to immune-checkpoint inhibitors. Significant work is ongoing to understand how the role of the microenvironment (including the gut microbiome) influences immune-evading mechanisms or immune-editing in CRC, ${ }^{163}$ and this should help unlock the potential of immunotherapy in this disease.

RR12.2: Employ our evolving understanding of the role of the tumour microenvironment in CRC to develop innovative therapies that modulate the microenvironment for clinical benefit.

\section{Living with and beyond CRC Current status}

Congruent with prioritisation of research to promote effective prevention, enable earlier more precise diagnosis and deliver optimal treatments to enhance CRC outcomes, there is a need for more research-informed approaches to improve HRQOL and enhance survivorship for the expanding population now living with and beyond CRC. Instruments such as the EORTC QLQ-CR29 questionnaire are invaluable in assessing HRQOL in CRC, ${ }^{164}$ while the recently introduced ESMO Magnitude of Clinical Benefit Scale ${ }^{165}$ includes HRQOL in its evaluation of benefit/value of new treatments. Despite this progress, there are still substantial gaps in our knowledge about optimising HRQOL; thus further research is required to inform appropriate intervention(s) and promote a responsive HRQOL agenda for the CRC survivor over the coming decade.

RG13: The need to increase understanding of health-related quality of life (HRQOL) issues and promote their resolution as part of 
a research effort to enhance survivorship for those living with and beyond CRC.

\section{Health-related quality of life}

A recent systematic review indicated that $>75 \%$ of reported studies addressing HRQOL in CRC were of inadequate methodological/reporting quality. ${ }^{166}$ Additionally, many HRQOL studies are retrospective; introduction of preplanned analyses would significantly enhance data quality, ${ }^{167}$ and identify those patients who might benefit from early discontinuation of induction therapy or continuation/de-escalation of active maintenance treatment. Immune-checkpoint targeting is an exciting new therapeutic modality, with unparalleled efficacy in MMR-deficient CRC, ${ }^{105} 160161$ but knowledge of both short-term and long-term HRQOL issues and PROMs are limited. More precise research is also required to improve understanding of the psychological consequences (eg, emotional reactions, survivorship guilt, lack of reintegration into normal life) and social challenges (eg, employment, self-esteem, discrimination) for those living with and beyond CRC. Development of evidence-based models that elucidate relevant predictors of $\mathrm{HRQOL}^{168}$ would help pinpoint individuals at risk and provide potential solutions to help resolve the clinical/psychosocial sequelae of CRC and their treatment.

RR13.1: Precisely characterise the landscape of HRQOL sequelae in patients living with and beyond CRC, including those in receipt of novel treatment approaches (eg, immunotherapy).

\section{Symptom management}

A high proportion of patients have troublesome, embarrassing and potentially disabling symptoms after surgery/radiotherapy for CRC. Many patients experience a permanent change in bowel habit after anterior rectal resection (AR), ${ }^{169}$ with major negative impacts on daily living. ${ }^{170}{ }^{171}$ A meta-analysis of $>3300 \mathrm{AR}$ patients has found a $35 \%$ incidence of faecal incontinence (FI) ${ }^{172}$ Following pelvic radiotherapy, GI symptoms are the most common chronic side effect, with $50 \%$ of patients reporting significant effects on HRQOL. ${ }^{173}$ Chronic FI frequently occurs after radiotherapy for rectal cancer. ${ }^{173}$

Published systematic reviews have found remarkably few intervention studies and no RCTs in patients with anterior resection syndrome. ${ }^{174-176}$ Hyperbaric oxygen has frequently been used to treat patients following pelvic radiotherapy, but a recent RCT demonstrated no benefit, highlighting the urgent need for new approaches. ${ }^{177}$ After radiotherapy, it is possible to improve symptoms with relatively low-cost interventions, ${ }^{178}{ }^{179}$ but studies of lifestyle interventions, self-management and choice of optimal support services are lacking.

We need to better understand which aspects of treatment cause symptoms and define their underlying mechanism, in order to test measures to prevent/ameliorate symptom development and treat symptoms when they are troublesome.

RR13.2: Elucidate the causes of symptoms following CRC treatment and develop viable solutions for their prevention and/or management.

\section{Lifestyle interventions}

Emerging evidence suggests that lifestyle interventions promoting increased physical activity, ${ }^{180}$ healthy eating ${ }^{181}$ and weight control can have significant benefits, but research on their impact following CRC treatment or during recurrence is limited. ${ }^{182} 183$ More longitudinal studies are required to underpin the evidence base for introduction of such interventions and to identify appropriate tools to measure their proposed benefits. ${ }^{184}$

RR13.3: Evaluate the evidence base and impact of lifestyle interventions, including increased physical activity and better nutrition in CRC.

\section{Survivorship}

Survivorship care planning must involve meaningful two-way dialogue. However, surveys reveal that only a minority of HCPs regularly discuss survivorship issues or provide survivorship care plans to those living beyond CRC. ${ }^{185}{ }^{186}$ It is imperative to implement research-informed National Cancer Survivorship Plans. ${ }^{187-189}$ Research to develop appropriate CRC survivorship care guidelines ${ }^{190}$ can underpin creation of relevant tools to nurture open and effective interactions between HCPs and CRC survivors, empowering a shared decision-making culture.

RR13.4: Develop research to support survivorship care planning and promote shared decision-making for people living with and beyond CRC.

\section{Overarching RGs that need to be addressed}

In addition to the thematic RGs outlined above, there are also several cross-cutting RGs raised by a number of the WGs.

RG14: Lack of coordination of CRC research and its funding, leading to fragmented efforts to elucidate the biology of the disease and translate this knowledge into new preventative agents, screening tools, diagnostics and therapeutics.

The need for a national cancer research forum

Congruent with the multidisciplinary team approach delivering optimal care to patients with CRC is the need to bring together the diverse expertise increasingly required to answer the complex research challenges outlined in this paper. Linking biologists, physical scientists and mathematicians can fuel development of testable chemoprevention models. Integrating epidemiological, bioinformatic, pathological and clinical expertise can underpin rational biomarker-informed clinical trial design. Capturing all of this expertise under the umbrella of a national CRC research conference in the UK, for example, would provide the impetus for a coordinated interdisciplinary approach to successfully address the critical challenges in CRC research.

RR14.1: Establish an annual national multidisciplinary CRC research conference that draws together the entire CRC community in a coordinated research effort.

\section{The need for data sharing}

A recurrent theme from a number of the WGs was the need to provide mechanisms and tools that enable sharing of the ever-expanding data outputs generated through CRC research. Sharing of genomic, clinical, epidemiological and lifestyle data can be challenging, but international collaborative efforts such as the Global Alliance for Genomics and Health ${ }^{191}$ provide a blueprint for effective but responsible data sharing in cancer that addresses the technical, ethical, legal and security barriers. ${ }^{192}{ }^{193}$ Development of bespoke data-analytic platforms, ${ }^{194}$ tailored to the requirements of the CRC community, could maximise the value of the rich sources of data being generated and yield significant benefits for CRC researchers, patients and society. 
RR14.2: Develop bespoke data-analytic platforms that maximise the value of CRC genomic, clinical, epidemiological and lifestyle data.

\section{Prioritising funding for $\mathrm{CRC}$ research}

As well as prioritising research activity, the BCUK's Critical Research Gaps in Colorectal Cancer Initiative provides an excellent opportunity for research funders (eg, research councils, cancer charities, non-governmental organisations) to concentrate their funding in particular areas of focus where there is a defined research need, and/or investigate the potential for collaborative research grant calls between complimentary research funding organisations. An example of this approach is the Medical Research Council-CRUK jointly funded Stratified Medicine in Colorectal Cancer consortium, ${ }^{157} 195$ which brings together diverse stakeholders in a research collaborative to develop predictive and prognostic markers that drive precision medicine approaches in CRC.

RR14.3: Prioritise research resource allocation to recognise research gaps and encourage collaborative research grant calls between complimentary research funding organisations.

RG15: Lack of effective communication strategies between healthcare professionals, patients with CRC/survivors, those at elevated risk of developing CRC, and the general public and varying levels of awareness of key risk factors, prevention options and benefits/risks associated with different treatment options.

\section{Closing the communication gap}

There are distinct challenges around CRC health literacy and communication between HCPs and patients with CRC/survivors, those at elevated risk of developing CRC and the general public. Patients are becoming increasingly empowered to make their own personalised health decisions; this should be encouraged and nurtured. However, awareness of personal CRC risk/risk factors, ${ }^{196} 197$ appropriate prevention options ${ }^{198}$ and benefits/ risks associated with treatments ${ }^{199}$ is variable. Patient-adapted educational materials and shared decision-making tools 200201 must be made available, empowering individual choice while facilitating formal assessment of 'what is or was the right choice' for that individual.

RR15.1: Development of patient and person-adapted educational materials and shared decision-making tools in order to empower individual choice.

Research into the most appropriate communication strategies for explaining risk and benefit in different settings (eg, cancer risk modification, surgery, adjuvant therapy) is crucial. Recent work on knowledge of, and attitudes to, CRC chemoprevention has highlighted that a majority of primary care physicians were unaware of the chemopreventive properties of aspirin. ${ }^{202}$ There is a need for better communication with patients about treatment-related symptoms, emphasising that it is legitimate to seek help (and not simply accept treatment-related complications as the price of a successful cure) and investigate both professionally led and self-help interventions.

From a patient communication perspective, PROMs play a key role in identifying specific needs, while also providing important information on outcomes. ${ }^{203}$ However, there are major variations in how PROMs are measured and employed. ${ }^{204}$ Studies should identify which PROMs best reflect the views/experiences of individuals living with and beyond CRC, and how they may signpost early indicators of disease recurrence.

Evidence is also required as to whether long-term access to a CRC nurse or other relevant HCP improves communication and shared decision-making, empowering survivors as active participants in their own care. ${ }^{205}$ A better understanding of why patients with CRC do or do not participate in RCTs would help facilitate recruitment and allow development of RCT protocols more relevant/acceptable to patients. ${ }^{206}$ A recent multinational survey indicated a high awareness of patients with breast, lung or CRC regarding the potential of precision medicine to deliver personalised care ${ }^{207}$ but highlighted important regional variations and the patient's need for additional information.

RR15.2: Embedding strategies that ensure appropriate communication of risk and benefit and best capture patient-reported outcome measures (PROM) in order to ensure optimal outcomes for patients, their families and carers, and those at risk of developing CRC.

Research addressing these diverse communications issues can help ensure that patients with $\mathrm{CRC}$ /survivors and those at risk of developing CRC receive optimal information and participate in their health-preserving decisions as equals.

\section{CONCLUSIONS}

In this position paper, we present the informed considerations of a wide-ranging multidisciplinary group of experts from UK-based research institutions, complemented by significant input from those affected by CRC. We articulate their collective viewpoint in a series of critical RGs and RRs (see online supplementary table 1), which if appropriately implemented would significantly impact on the prevention, early diagnosis, treatment and improved quality of life for people living with and beyond CRC. Prioritisation of CRC research activity, supported by effective policy decisions and appropriate resource allocations, will help us tackle this life-threatening, debilitating disease that kills $\sim 800000$ of our citizens globally each year.

\section{Author affiliations}

${ }^{1}$ Centre for Cancer Research and Cell Biology, Queen's University Belfast, Belfast, UK ${ }^{2}$ Bowel Cancer UK, London, UK

${ }^{3}$ School of Medicine, Cardiff University, Cardiff, UK

${ }^{4}$ Research into Cancer Prevention and Screening, University of Dundee, Dundee, UK

${ }^{5}$ Department of Radiology, Royal Marsden Hospital, Sutton, UK

${ }^{6}$ Department of Colorectal Surgery, Addenbrooke's Hospital, Cambridge, UK

${ }^{7}$ Hepatobiliary Surgery Unit, Aintree University Hospital, Liverpool, UK

${ }^{8}$ Faculty of Health and Medical Sciences, University of Surrey, Guildford, UK

${ }^{9}$ Department of Oncology, University College London Cancer Institute, London, UK

${ }^{10}$ Leeds Institute of Biomedical and Clinical Sciences, University of Leeds, Leeds, UK

${ }^{11}$ Molecular and Population Genetics Laboratory, University of Oxford, Oxford, UK

${ }^{12}$ Centre for Surgical Research, University of Bristol, Bristol, UK

${ }^{13}$ Family History of Bowel Cancer Clinic, Imperial College London, London, UK

${ }^{14}$ School of Life Sciences, University of Dundee, Dundee, UK

${ }^{15}$ Florence Nightingale Faculty of Nursing and Midwifery, King's College London, London, UK

${ }^{16}$ Research Department of Pathology, University College London Medical School, London, UK

${ }^{17}$ Leicester Cancer Research Centre, University of Leicester, Leicester, UK

${ }^{18}$ Atticus Consultants Ltd, Croydon, UK

${ }^{19}$ Institute of Cancer and Genomic Sciences, University of Birmingham, Birmingham, UK

Acknowledgements We would like to thank the contribution of all our Working Group members and those who took part in the BCUK-RG Evaluation Day (online supplementary appendix 2). Bowel Cancer UK staff member Sam Pearce was responsible for coordinating and delivering the logistics of the process, and Dr Julia Ambler was responsible for manuscript coordination. We thank Dr Alexis Willet who provided editorial assistance on behalf of Punch Consulting. We are grateful to Charles Russel Speechlys (5 Fleet Place, London) and Lewis PR (30 Millbank, London) for providing meeting spaces pro bono.

Collaborators Working Group members ( ${ }^{*}$ denotes Bowel Cancer UK Medical Advisory Board member, + denotes Bowel Cancer UK Scientific Advisory Board member, and $\beta$ denotes former or current Bowel Cancer UK Trustee): Professor Emeritus Sam H Ahmedzai, Dr Jervoise Andreyev*, Professor Wendy Atkin*, Mr 
Simon Bach, Dr David Brewster, Professor Karen Brown, Professor Sir John Burn*+ Professor Jean-Baptiste Cazier, Dr lan Chau, Professor Jeremy Cheadle, Dr Vicky Coyle, Professor David Cunningham, Professor Julian Downward, Professor Malcom Dunlop, Professor Callum Fraser, Dr Marco Gerlinger, Dr Adam Glaser, Professor Vicky Goh, Professor David González de Castro, Professor Trevor Graham, Mr John Griffith, Professor Steve Halligan, Professor Willie Hamilton*, Mrs Rachel Haynes, Dr Georgina Hold, Professor Richard Houlston, Dr Gill Hubbard, Dr Tariq Iqba, Mrs Sandra Irvine, Dr Tim Iveson*, Professor Dan Longley, Dr Ultan McDermott, Mr Michael Machesney*, Professor Jane Maher, Professor Julian Marchesi, Professor Tim Maughan, Professor Gary Middleton, Mrs Barbara Moss, Mr Mark Moss, Dr Peter Murchie, Professor Matt Rutter, Dr Leslie Samuel, Professor Owen Sansom, Professor John Saxton, Dr Ed Seward, Dr Ricky Sharma, Dr Andrea Sottoriva, Professor Will Steward, Dr Christian Von Wagner, Professor Ann Williams, and Professor Doug Winton. BCUK-RG Evaluation Day participants: Mr Nicholas Arbuthnot, Mrs Lindy Berkman, Miss Nicola Bloor, Mr Victor Boulter, Mrs Ann Cole, Mr Mark Davies, Mrs Julie Hepburn, Mr Joe Higgins ${ }^{\beta}$, Mr Georgy Holden, Dr Alexandra E Irvine, Mr Nick Jakowiw, Mr lan Jackson, Mrs Monica Jefford, Mrs Barbara Moss, Mr Mark Moss, Mr Peter O'Sullivan, Mr Clint Robertson, Mrs Tracy Smith, Mr Phil Stocker, and Mrs Gillian Sweetman.

Contributors Conception and design of study: ML, DA, LMW, RHW, IT. Acquisition of data through questionnaires, attending meetings and drafting of initial reports: $M L, D A, R A A, A S A, G B, N S F, S W F, S P H, D H, M A H, A G K M, K J M, I N, C N, M R N, R J C S$, ALT, LMW, RHW, IT, SHA, JA, NA, WA, SB, LB, NB, VB, DB, KB, JB, JBC, IC, JC, AC, VC, $D C, M D, J D, M D, C F, M G, A G, V G, D G d C, T G, J G, S H, W H, J H, R H, J H, G H, G H, R H, G H$ TI, SI, TI, NJ, IJ, MJ, DL, UM, MM, JM, JM, TM, GM, BM, MM, PM, POS, CR, MR; LS, OS, JS, ES, RS, TS, AS, WS, PS, GS, CVW, AW, DW. Drafting of the manuscript: ML, DA, RAA, ASA, GB, NSF, SWF, SPH, DH, MAH, VHK, AGKM, KJM, IN, CN, MN, RJCS, ALT, LW, RHW, IT. Revising the manuscript critically for important intellectual content: ML, DA, RAA, ASA, GB, NSF, SWF, SPH, DH, MAH, VHK, AGKM, KJM, IN, CN, MN, RJCS, ALT, LW, RHW, IT. Approval of the version of the manuscript to be published: ML, DA, RAA, ASA, GB, NSF, SWF, SPH, DH, MAH, VHK, AGKM, KJM, IN, CN, MN, RJCS, ALT, LW, RHW, IT.

Funding The study was funded by Bowel Cancer UK, the Norman Foster Foundation and the Tom Simms Memorial Fund at Queen's University Belfast.

Competing interests ML reports support from Pfizer, outside the submitted work; DA reports grants from the Norman Foster Foundation, grants from the Tom Simms Memorial Fund at Queen's University Belfast, during the conduct of the study; Dr Andreyev reports other from Entrinsic Health Solutions, Inc and personal fees from Macmillan Cancer Support, outside the submitted work; Professor Atkin reports grants from Cancer Research UK, outside the submitted work; Mr Bach reports personal fees from Ethicon Inc, outside the submitted work; Professor Burn has a patent A novel panel of short coding repeats suitable for high-throughput detection of microsatellite instability pending to Newcastle University; Dr Chau reports grants from Eli-Lily, Janssen-Cilag, Sanofi Oncology, Merck-Serono, and Novartis, personal fees from Taiho, Pfizer, Amgen, Eli-Lily, outside the submitted work; Professor Cheadle has a patent MUTYH gene variants licensed to Myriad Genetics and receives royalties; Professor Cunningham reports grants from Amgen, AstraZeneca, Bayer, Celgene, Medimmune, Merck Serono, Merrimack, and Sanofi, outside the submitted work; Professor Fraser reports personal fees from Immunostics Inc, Ocean, NJ, USA, Kyowa, Tokyo, Japan, and support for travel from Alpha Labs Ltd, Eastleigh, Hants, UK, during the conduct of the study; DH reports MRC CASE Award with Merck Serono for project unrelated to this submission and research support from Merck Serono for project unrelated to this submission; $\mathrm{MH}$ reports other from consultancy for Thetis Pharma, outside the submitted work; CN reports personal fees from Takeda and Ferring, outside the submitted work; Dr Sharma reports grants, personal fees and other from Sirtex, grants, personal fees and other from BTG, during the conduct of the study; AT reports personal fees from BMS Advisory Board, Roche Speaker Panel, Amgen Advisory Board, and Servier Advisory Board, outside the submitted work; LMW reports personal fees from Atticus Consultants Ltd, during the conduct of the study; RW reports personal fees from BMS Advisory Board, Clovis Oncology Advisory Board, Halozyme Advisory Board, Amgen Advisory Board, Servier Advisory Board, and Sirtex Independent Data Monitoring and Safety Committee, all outside the submitted work. RA, Professor Ahmedzai, ASA, Mr Arbuthnot, Mrs Berkman, Miss Bloor, Mr Boulter, Mrs Cole, Dr Brewster, GB, Professor Cazier, Dr Coyle, Mr Davies, Professor Downward, Professor Dunlop, NSF, SF, Dr Gerlinger, Dr Glaser, Professor Goh, Professor González De Castro, Dr Graham, Mr Griffith, Professor Halligan, SPH, Professor Hamilton, Mrs Hepburn, Dr Hold, Mr Holden, Professor Houlston, Dr Hubbard, Dr Iqbal, Dr Irvine, Dr Iveson, Mr Jackson, Mr Jakowiw, Mrs Jefford, Professor Longley, Dr McDermott, AGKM, Mr Machesney, Professor Maher, Professor Marchesi, Professor Maughan, Professor Middleton, Mr Moss, Mrs Moss, KJM, Dr Murchie, IN, MRN, Mr O'Sullivan, Mr Robertson, Professor Rutter, Dr Sansom, Dr Samuel, Professor Saxton, Dr Seward, Mrs Smith, Dr Sottoriva, RS, Professor Steward, Mr Stocker, Mrs Sweetman, IT, Dr Von Wagner and Professor Williams have nothing to disclose.

Provenance and peer review Not commissioned; externally peer reviewed.
Open Access This is an Open Access article distributed in accordance with the Creative Commons Attribution Non Commercial (CC BY-NC 4.0) license, which permits others to distribute, remix, adapt, build upon this work non-commercially, and license their derivative works on different terms, provided the original work is properly cited and the use is non-commercial. See: http://creativecommons.org/ licenses/by-nc/4.0/

(c) Article author(s) (or their employer(s) unless otherwise stated in the text of the article) 2018. All rights reserved. No commercial use is permitted unless otherwise expressly granted.

\section{REFERENCES}

1 Arnold M, Sierra MS, Laversanne M, et al. Global patterns and trends in colorectal cancer incidence and mortality. Gut 2017;66:683-91.

2 Cancer Research UK. Bowel cancer statistics. http://www.cancerresearchuk.org/ health-professional/cancer-statistics/statistics-by-cancer-type/bowel-cancer (accessed 08 Sep 2017)

3 The American Cancer Society. http://www.cancer.org/acs/groups/content/@ internationalaffairs/documents/document/acspc-026203.pdf (accessed 08 Sep 2017).

4 Mariotto $A B$, Yabroff KR, Shao Y, et al. Projections of the cost of cancer care in the United States: 2010-2020. J Natl Cancer Inst 2011;103:117-28.

5 Luengo-Fernandez R, Leal J, Gray A, et al. Economic burden of cancer across the European Union: a population-based cost analysis. Lancet Oncol 2013;14:1165-74

6 National Cancer Institute. https://fundedresearch.cancer.gov/nciportfolio/search/get? site=Colon\%2fRectum\&fy=PUB2014 (accessed 08 Sep 2017).

7 Cancer Research UK. How much we spend on research. http://www. cancerresearchuk.org/how-much-we-spend-on-research (accessed 08 Sep 2017).

8 Eccles SA, Aboagye EO, Ali S, et al. Critical research gaps and translational priorities for the successful prevention and treatment of breast cancer. Breast Cancer Res 2013; 15:R92.

9 Lobert VH, Mouradov D, Heath JK. Focusing the spotlight on the zebrafish intestine to illuminate mechanisms of colorectal cancer. Adv Exp Med Biol 2016:916:411-37.

10 Rasmussen LJ, Heinen CD, Royer-Pokora B, et al. Pathological assessment of mismatch repair gene variants in Lynch syndrome: past, present, and future. Hum Mutat 2012;33:1617-25.

11 Nusse R, Clevers H. Wnt/ $\beta$-catenin signaling, disease, and emerging therapeutic modalities. Cell 2017;169:985-99.

12 Maccaroni E, Bracci R, Giampieri R, et al. Prognostic impact of mismatch repair genes germline defects in colorectal cancer patients: are all mutations equal? Oncotarget 2015;6:38737-48.

13 Guinney J, Dienstmann R, Wang X, et al. The consensus molecular subtypes of colorectal cancer. Nat Med 2015;21:1350-6.

14 Isella C, Brundu F, Bellomo SE, et al. Selective analysis of cancer-cell intrinsic transcriptional traits defines novel clinically relevant subtypes of colorectal cancer. Nat Commun 2017:8:15107.

15 Dunne PD, Alderdice M, O'Reilly PG, et al. Cancer-cell intrinsic gene expression signatures overcome intratumoural heterogeneity bias in colorectal cancer patient classification. Nat Commun 2017;8:15657.

16 Isella C, Terrasi A, Bellomo SE, et al. Stromal contribution to the colorectal cancer transcriptome. Nat Genet 2015;47:312-9.

17 Calon A, Lonardo E, Berenguer-Llergo A, et al. Stromal gene expression defines poorprognosis subtypes in colorectal cancer. Nat Genet 2015;47:320-9.

18 Dunne PD, McArt DG, Bradley CA, et al. Challenging the cancer molecular stratification dogma: intratumoral heterogeneity undermines consensus molecular subtypes and potential diagnostic value in colorectal cancer. Clin Cancer Res 2016;22:4095-104.

19 Naxerova K, Reiter JG, Brachtel E, et al. Origins of lymphatic and distant metastases in human colorectal cancer. Science 2017;357:55-60.

20 Villalba M, Evans SR, Vidal-Vanaclocha F, et al. Role of TGF- $\beta$ in metastatic colon cancer: it is finally time for targeted therapy. Cell Tissue Res 2017:29-39.

21 Hong AW, Meng Z, Guan KL. The Hippo pathway in intestinal regeneration and disease. Nat Rev Gastroenterol Hepatol 2016;13:324-37.

22 Xia T, Konno H, Ahn J, et al. Deregulation of STING signaling in colorectal carcinoma constrains DNA damage responses and correlates with tumorigenesis. Cell Rep 2016;14:282-97

23 Jackstadt R, Sansom OJ. Mouse models of intestinal cancer. J Pathol 2016;238:141-51.

24 Su LK, Kinzler KW, Vogelstein B, et al. Multiple intestinal neoplasia caused by a mutation in the murine homolog of the APC gene. Science 1992;256:1114.

25 Bertotti A, Migliardi G, Galimi F, et al. A molecularly annotated platform of patientderived xenografts ("xenopatients") identifies HER2 as an effective therapeutic target in cetuximab-resistant colorectal cancer. Cancer Discov 2011;1:508-23.

26 Sato T, Vries RG, Snippert HJ, et al. Single Lgr 5 stem cells build crypt-villus structures in vitro without a mesenchymal niche. Nature 2009;459:262-5. 
27 Omar Al-Hassi H, Ng O, Brookes M. Tumour-associated and non-tumour-associated microbiota in colorectal cancer. Gut 2017 (Epub ahead of print: 04 May 2017).

28 Simonds NI, Ghazarian AA, Pimentel CB, et al. Review of the gene-environment interaction literature in cancer: what do we know? Genet Epidemiol 2016;40:356-65.

29 Peters U, Bien S, Zubair N, et al. Genetic architecture of colorectal cancer. Gut 2015;64:1623-36.

30 Chubb D, Broderick P, Dobbins SE, et al. Rare disruptive mutations and their contribution to the heritable risk of colorectal cancer. Nat Commun 2016;7:11883.

31 Vogtmann E, Goedert JJ. Epidemiologic studies of the human microbiome and cancer. Br J Cancer 2016;114:237-42.

32 Torres Stone RA, Waring ME, Cutrona SL, et al. The association of dietary quality with colorectal cancer among normal weight, overweight and obese men and women: a prospective longitudinal study in the USA. BMJ Open 2017;7:e015619.

33 Aleksandrova $\mathrm{K}$, Pischon $\mathrm{T}$, Jenab $\mathrm{M}$, et al. Combined impact of healthy lifestyle factors on colorectal cancer: a large European cohort study. BMC Med 2014;12:168

34 van Duijnhoven FJ, Bueno-De-Mesquita HB, Calligaro M, et al. Blood lipid and lipoprotein concentrations and colorectal cancer risk in the European Prospective Investigation into Cancer and Nutrition. Gut 2011;60:1094-102.

35 González N, Prieto I, Del Puerto-Nevado L, et al. 2017 update on the relationship between diabetes and colorectal cancer: epidemiology, potential molecular mechanisms and therapeutic implications. Oncotarget 2017:8:18456-85.

$36 \mathrm{Nan} \mathrm{H}$, Hutter CM, Lin Y, et al. Association of aspirin and NSAID use with risk of colorectal cancer according to genetic variants. JAMA 2015;313:1133-42.

37 Weinberg DS, Myers RE, Keenan E, et al. Genetic and environmental risk assessment and colorectal cancer screening in an average-risk population: a randomized trial. Ann Intern Med 2014;161:537-45.

38 Cancer Prevention Program. Genetics and epidemiology of colorectal cancer consortium (GECCO). http://www.fredhutch.org/en/labs/phs/projects/cancerprevention/projects/gecco.html (accessed 08 Sep 2017).

39 National Cancer Institute. Epidemiology and genomics research program. https://epi. grants.cancer.gov/gameon/ (accessed 08 Sep 2017)

40 Zeng C, Matsuda K, Jia WH, et al. Identification of susceptibility loci and genes for colorectal cancer risk. Gastroenterology 2016;150:1633-45.

$41 \mathrm{Hsu} \mathrm{L}$, Jeon J, Brenner $\mathrm{H}$, et al. A model to determine colorectal cancer risk using common genetic susceptibility loci. Gastroenterology 2015;148:1330-9.

42 Scarbrough PM, Weber RP, Iversen ES, et al. A cross-cancer genetic association analysis of the DNA repair and DNA damage signaling pathways for lung, ovary, prostate, breast, and colorectal cancer. Cancer Epidemiol Biomarkers Prev 2016;25:193-200.

43 Zhang B, Jia WH, Matsuda K, et al. Large-scale genetic study in east asians identifies six new loci associated with colorectal cancer risk. Nat Genet 2014;46:533-42.

44 Wang H, Burnett T, Kono S, et al. Trans-ethnic genome-wide association study of colorectal cancer identifies a new susceptibility locus in VTI1A. Nat Commun 2014;5:4613

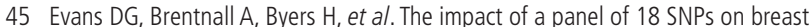
cancer risk in women attending a UK familial screening clinic: a case-control study. $J$ Med Genet 2017:54:111-3.

46 Shi J, Park JH, Duan J, et al. Winner's curse correction and variable thresholding improve performance of polygenic risk modeling based on genome-wide association study summary-level data. PLoS Genet 2016;12:e1006493.

47 Kantor ED, Hutter CM, Minnier J, et al. Gene-environment interaction involving recently identified colorectal cancer susceptibility Loci. Cancer Epidemiol Biomarkers Prev 2014;23:1824-33.

48 Figueiredo JC, Hsu L, Hutter CM, et al. on behalf of CCFR; GECCO. Genomewide diet-gene interaction analyses for risk of colorectal cancer. PLoS Genet 2014;10:e1004228.

49 Park SY, Boushey CJ, Wilkens LR, et al. High-quality diets associate with reduced risk of colorectal cancer: analyses of diet quality indexes in the multiethnic cohort. Gastroenterology 2017;153:386-94.

50 Gong J, Hutter CM, Newcomb PA, et al. Genome-wide interaction analyses between genetic variants and alcohol consumption and smoking for risk of colorectal cancer. PLoS Genet 2016;12:e1006296.

51 Monahan KJ, Alsina D, Bach S, et al. Urgent improvements needed to diagnose and manage Lynch syndrome. BMJ 2017;356:j1388

52 Chamnan P, Simmons RK, Khaw KT, et al. Estimating the population impact of screening strategies for identifying and treating people at high risk of cardiovascular disease: modelling study. BMJ 2010:340:c1693.

53 Anderson AS, Caswell S, Macleod M, et al. Awareness of lifestyle and colorectal cancer risk: findings from the BeWEL study. Biomed Res Int 2015;2015:1-5.

54 National Cancer Research Center. How was research funding from NCRI Partners spent in 2015? http://www.ncri.org.uk/wp-content/uploads/2016/06/2016-NCRICaRD-210-x-297.pdf (accessed 08 Sep 2017).

55 Movahedi M, Bishop DT, Macrae F, et al. Obesity, aspirin, and risk of colorectal cancer in carriers of hereditary colorectal cancer: a prospective investigation in the CAPP2 study. J Clin Oncol 2015;33:3591-7.
56 World Cancer Research Fund. How was research funding from NCRI Partners spent in 2015? http://www.wcrf.org/sites/default/files/CUP\%20Colorectal\%20Report_ 2017_Digital.pdf (accessed 08 Sep 2017).

57 Garrett WS. Cancer and the microbiota. Science 2015;348:80-6.

58 Arnold M, Leitzmann M, Freisling $H$, et al. Obesity and cancer: An update of the global impact. Cancer Epidemiol 2016;41:8-15.

59 Ma Y, Yang Y, Wang F, et al. Obesity and risk of colorectal cancer: a systematic review of prospective studies. PLoS One 2013:8:e53916.

60 Lauby-Secretan B, Scoccianti C, Loomis D, et al. Body fatness and cancer-viewpoint of the IARC working group. N Engl J Med 2016;375:794-8.

61 Wolin KY, Yan Y, Colditz GA, et al. Physical activity and colon cancer prevention: a meta-analysis. Br J Cancer 2009;100:611-6.

62 Burn J, Gerdes AM, Macrae F, et al. Long-term effect of aspirin on cancer risk in carriers of hereditary colorectal cancer: an analysis from the CAPP2 randomised controlled trial. Lancet 2011:378:2081-7.

63 Drew DA, Cao Y, Chan AT. Aspirin and colorectal cancer: the promise of precision chemoprevention. Nat Rev Cancer 2016:16:173-86.

64 Bibbins-Domingo K, U.S. Preventive Services Task Force. Aspirin use for the primary prevention of cardiovascular disease and colorectal cancer: U.S. preventive services task force recommendation statement. Ann Intern Med 2016;164:836-45.

65 Cuzick J, Thorat MA, Bosetti C, et al. Estimates of benefits and harms of prophylactic use of aspirin in the general population. Ann Oncol 2015;26:47-57.

66 Smith SG, Foy R, McGowan J, et al. General practitioner attitudes towards prescribing aspirin to carriers of Lynch Syndrome: findings from a national survey. Fam Cancer 2017:509-16.

67 Patterson RE, Colditz GA, Hu FB, et al. The 2011-2016 transdisciplinary research on energetics and cancer (TREC) initiative: rationale and design. Cancer Causes Control 2013:24:695-704

68 Bhatt AP, Redinbo MR, Bultman SJ. The role of the microbiome in cancer development and therapy. CA Cancer J Clin 2017;67:326-44.

69 Bultman SJ. The microbiome and its potential as a cancer preventive intervention. Semin Oncol 2016;43:97-106.

70 Moug SJ, Bryce A, Mutrie N, et al. Lifestyle interventions are feasible in patients with colorectal cancer with potential short-term health benefits: a systematic review. Int $J$ Colorectal Dis 2017:32:765-75.

71 Anderson AS, Mackison D, Boath C, et al. Promoting changes in diet and physical activity in breast and colorectal cancer screening settings: an unexplored opportunity for endorsing healthy behaviors. Cancer Prev Res 2013;6:165-72.

72 Benson VS, Atkin WS, Green J, et al. And international colorectal cancer screening network. toward standardizing and reporting colorectal cancer screening indicators on an international level: the international colorectal cancer screening network. Int J Cancer 2012:130:2961-73.

73 Moss S, Mathews C, Day TJ, et al. Increased uptake and improved outcomes of bowel cancer screening with a faecal immunochemical test: results from a pilot study within the national screening programme in England. Gut 2017:66:1631-44.

74 Digby J, Fraser CG, Carey FA, et al. Interval cancers using a quantitative faecal immunochemical test (FIT) for haemoglobin when colonoscopy capacity is limited. J Med Screen 2016;23:130-4.

75 Atkin W, Wooldrage K, Parkin DM, et al. Long term effects of once-only flexible sigmoidoscopy screening after 17 years of follow-up: the UK flexible sigmoidoscopy screening randomised controlled trial. Lancet 2017;389:1299-311.

76 Peacock O, Clayton S, Atkinson F, et al. 'Be Clear on Cancer': the impact of the UK national bowel cancer awareness campaign. Colorectal Dis 2013;15:963-7.

77 Bethune R, Marshall MJ, Mitchell SJ, et al. Did the 'be clear on bowel cancer' public awareness campaign pilot result in a higher rate of cancer detection? Postgrad Med J 2013;89:390-3

78 Mowat C, Digby J, Strachan JA, et al. Faecal haemoglobin and faecal calprotectin as indicators of bowel disease in patients presenting to primary care with bowel symptoms. Gut 2016;65:1463-9.

79 NICE. Quantitative faecal immunochemical tests to guide referral for colorectal cancer in primary care. https://www.nice.org.uk/guidance/dg30 (accessed 08 Sep 2017).

80 Bretthauer M, Kaminski MF, Løberg M, et al. Nordic-european initiative on colorectal cancer (NordICC) study group. population-based colonoscopy screening for colorectal cancer: a randomized clinical trial. JAMA Intern Med 2016:176:894-902.

81 You JJ, Liu Y, Kirby J, et al. Virtual colonoscopy, optical colonoscopy, or fecal occult blood testing for colorectal cancer screening: results of a pilot randomized controlled trial. Trials 2015;16:296.

82 Sali L, Mascalchi M, Falchini M, et al. Reduced and full-preparation CT colonography, fecal immunochemical test, and colonoscopy for population screening of colorectal cancer: a randomized trial. J Nat/ Cancer Inst 2016;108:djv319.

83 Hewitson P, Glasziou P, Watson E, et al. Cochrane systematic review of colorectal cancer screening using the fecal occult blood test (hemoccult): an update. Am J Gastroentero/ 2008:103:1541-9.

84 McDonald PJ, Strachan JA, Digby J, et al. Faecal haemoglobin concentrations by gender and age: implications for population-based screening for colorectal cancer. Clin Chem Lab Med 2011;50:935-40. 
85 Birks J, Bankhead C, Holt TA, et al. Evaluation of a prediction model for colorectal cancer: retrospective analysis of 2.5 million patient records. Cancer Med 2017:6:2453-60

86 Imperiale TF, Ransohoff DF, Itzkowitz SH, et al. Multitarget stool DNA testing for colorectal-cancer screening. N Engl J Med 2014;370:1287-97.

87 Song L, Yu H, Jia J, et al. A systematic review of the performance of the SEPT9 gene methylation assay in colorectal cancer screening, monitoring, diagnosis and prognosis. Cancer Biomark 2017; 18:425-32.

88 Sonoda H, Kohnoe S, Yamazato T, et al. Colorectal cancer screening with odour material by canine scent detection. Gut 2011;60:814-9.

89 Tan CR, Zhou L, El-Deiry WS. Circulating tumor cells versus circulating tumor DNA in colorectal cancer: pros and cons. Curr Colorectal Cancer Rep 2016;12:151-61.

90 Yu J, Feng Q, Wong SH, et al. Metagenomic analysis of faecal microbiome as a tool towards targeted non-invasive biomarkers for colorectal cancer. Gut 2017;66:70-8.

91 Muguruma N, Tanaka K, Teramae S, et al. Colon capsule endoscopy: toward the future. Clin J Gastroenterol 2017;10:1-6.

92 Tie J, Wang Y, Tomasetti C, et al. Circulating tumor DNA analysis detects minimal residual disease and predicts recurrence in patients with stage II colon cancer. $\mathrm{SCi}$ Trans/ Med 2016;8:346ra92.

93 Schøler LV, Reinert T, Ørntoft MW, et al. Clinical implications of monitoring circulating tumor DNA in patients with colorectal cancer. Clin Cancer Res 2017:23:5437-45.

94 Brierley JD, Gospodarowicz MK, Wittekind C, eds. TNM classification of malignant tumours. 8th ed. Oxford: Wiley-Blackwell, 2016.

95 Edge SB. American Joint Committee on Cancer. AJCC cancer staging manual. 7th ed. New York: Springer, 2010.

96 Lugli A, Kirsch R, Ajioka Y, et al. Recommendations for reporting tumor budding in colorectal cancer based on the international tumor budding consensus conference (ITBCC) 2016. Mod Pathol 2017;30:1299-311.

97 Galon J, Mlecnik B, Bindea G, et al. Towards the introduction of the 'Immunoscore' in the classification of malignant tumours. J Pathol 2014;232:199-209.

98 Pathology and prognostic determinants of colorectal cancer. https://www.uptodate. com/contents/pathology-and-prognostic-determinants-of-colorectal-cancer (accessed 08 Sep 2017).

99 Amin MB, Greene FL, Edge SB, et al. The eighth edition AJCC cancer staging manual: continuing to build a bridge from a population-based to a more "personalized" approach to cancer staging. CA Cancer J Clin 2017:67:93-9.

100 Cancer Genome Atlas Network. Comprehensive molecular characterization of human colon and rectal cancer. Nature 2012:487:330-7.

101 Paasinen-Sohns A, Koelzer VH, Frank A, et al. Single-center experience with a targeted next generation sequencing assay for assessment of relevant somatic alterations in solid tumors. Neoplasia 2017;19:196-206.

102 De Roock W, De Vriendt V, Normanno N, et al. KRAS, BRAF, PIK3CA, and PTEN mutations: implications for targeted therapies in metastatic colorectal cancer. Lancet Oncol 2011;12:594-603.

103 Lee AM, Shi Q, Pavey E, et al. DPYD variants as predictors of 5-fluorouracil toxicity in adjuvant colon cancer treatment (NCCTG N0147). J Natl Cancer Inst 2014;106:dju298.

104 Yeh YS, Tsai HL, Huang CW, et al. Prospective analysis of UGT1A1 promoter polymorphism for irinotecan dose escalation in metastatic colorectal cancer patients treated with bevacizumab plus FOLFIRI as the first-line setting: study protocol for a randomized controlled trial. Trials 2016:17:17-46.

105 Le DT, Uram JN, Wang H, et al. PD-1 Blockade in tumors with mismatch-repair deficiency. N Engl J Med 2015:372:2509-20.

106 De Sousa E Melo F, Wang X, Jansen M, et al. Poor-prognosis colon cancer is defined by a molecularly distinct subtype and develops from serrated precursor lesions. Nat Med 2013:19:614-8

107 Sadanandam A, Lyssiotis CA, Homicsko K, et al. A colorectal cancer classification system that associates cellular phenotype and responses to therapy. Nat Med 2013;19:619-25

108 Marisa L, de Reyniès A, Duval A, et al. Gene expression classification of colon cancer into molecular subtypes: characterization, validation, and prognostic value. PLoS Med 2013;10:e1001453.

109 Li G, Bankhead P, Dunne PD, et al. Embracing an integromic approach to tissue biomarker research in cancer: Perspectives and lessons learned. Brief Bioinform 2017; 18:634-46

110 Harpaz N, Polydorides AD. Colorectal dysplasia in chronic inflammatory bowel disease: pathology, clinical implications, and pathogenesis. Arch Pathol Lab Med 2010;134:876-95.

111 Coverlizza S, Risio M, Ferrari A, et al. Colorectal adenomas containing invasive carcinoma. pathologic assessment of lymph node metastatic potential. Cancer 1989:64:1937-47.

112 Beaton C, Twine CP, Williams GL, et al. Systematic review and meta-analysis of histopathological factors influencing the risk of lymph node metastasis in early colorectal cancer. Colorectal Dis 2013;15:788-97.

113 von Karsa L, Patnick J, Segnan N, et al. European guidelines for quality assurance in colorectal cancer screening and diagnosis: overview and introduction to the full supplement publication. Endoscopy 2013;45:51-9.
114 Kannarkatt J, Joseph J, Kurniali PC, et al. Adjuvant chemotherapy for stage II colon cancer: a clinical dilemma. J Oncol Pract 2017;13:233-41.

115 Gray R, Barnwell J, McConkey C, et al. Adjuvant chemotherapy versus observation in patients with colorectal cancer: a randomised study. Lancet 2007:370:2020-9.

116 O'Connell MJ, Campbell ME, Goldberg RM, et al. Survival following recurrence in stage II and III colon cancer: findings from the ACCENT data set. J Clin Oncol 2008;26:2336-41

117 Kopetz S, Tabernero J, Rosenberg R, et al. Genomic classifier ColoPrint predicts recurrence in stage II colorectal cancer patients more accurately than clinical factors. Oncologist 2015;20:127-33.

118 André T, Boni C, Mounedji-Boudiaf L, et al. Oxaliplatin, fluorouracil, and leucovorin as adjuvant treatment for colon cancer. N Engl J Med 2004;350:2343-51.

119 Kobayashi $\mathrm{H}$, Mochizuki H, Sugihara K, et al. Characteristics of recurrence and surveillance tools after curative resection for colorectal cancer: a multicenter study. Surgery 2007;141:67-75.

120 Stålhammar G, Fuentes Martinez N, Lippert M, et al. Digital image analysis outperforms manual biomarker assessment in breast cancer. Mod Pathol 2016;29:318-29

121 Life SciencesIndustrial Strategy. A report to the Government from the life sciences sector. https://www.gov.uk/government/uploads/system/uploads/attachment_data/ file/ 640696/life-sciences-industrial-strategy.pdf (accessed 08 Sep 2017).

122 Genomics Education Programme. Developing people for health and healthcare. https://www.genomicseducation.hee.nhs.uk/ (accessed 08 Sep 2017).

123 Haspel RL, Rinder HM, Frank KM, et al. The current state of resident training in genomic pathology: a comprehensive analysis using the resident in-service examination. Am J Clin Pathol 2014;142:445-51.

124 Kuhry E, Schwenk WF, Gaupset R, et al. Long-term results of laparoscopic colorectal cancer resection. Cochrane Database Syst Rev 2008:2:CD003432.

125 Veldkamp R, Kuhry E, Hop WC, et al. Laparoscopic surgery versus open surgery for colon cancer: short-term outcomes of a randomised trial. Lancet Oncol 2005;6:477-84

126 Morris EJA, Finan PJ, Spencer K, et al. Wide Variation in the Use of Radiotherapy in the Management of Surgically Treated Rectal Cancer Across the English National Health Service. Clin Oncol 2016;28:522-31.

127 Klinkhammer-Schalke M, Lindberg P, Koller M, et al. Direct improvement of quality of life in colorectal cancer patients using a tailored pathway with quality of life diagnosis and therapy (DIQOL): study protocol for a randomised controlled trial. Trials 2015;16:460.

128 Department of Oncology. Roosevelt Drive Oxford. https://www.oncology.ox.ac.uk/ trial/scot (accessed 08 Sep 2017).

129 Shi Q, Sobrero AF, Shields AF, et al. Prospective pooled analysis of six phase III trials investigating duration of adjuvant (adjuv) oxaliplatin-based therapy (3 vs 6 months) for patients (pts) with stage III colon cancer (CC): the IDEA (International Duration Evaluation of Adjuvant chemotherapy) collaboration. J Clin Oncol 2017;35(18_ suppl):LBA1.

130 Coyle C, Cafferty FH, Rowley S, et al. ADD-ASPIRIN: A phase III, double-blind, placebo controlled, randomised trial assessing the effects of aspirin on disease recurrence and survival after primary therapy in common non-metastatic solid tumours. Contemp Clin Trials 2016;51:56-64.

131 Courneya KS, Booth CM, Gill S, et al. The colon health and life-long exercise change trial: a randomized trial of the national cancer institute of canada clinical trials group. Curr Oncol 2008;15:279-85

132 Foxtrot Collaborative Group. Feasibility of preoperative chemotherapy for locally advanced, operable colon cancer: the pilot phase of a randomised controlled trial. Lancet Oncol 2012;13:1152-60.

133 Richards T, Coulter A, Wicks P. Time to deliver patient centred care. BMJ 2015:350:h530.

134 Heald RJ, Beets G, Carvalho C. Report from a consensus meeting: response to chemoradiotherapy in rectal cancer - predictor of cure and a crucial new choice for the patient: on behalf of the Champalimaud 2014 Faculty for 'Rectal cancer: when NOT to operate'. Colorectal Dis 2014;16:334-7.

135 Renehan AG, Malcomson L, Emsley R, et al. Watch-and-wait approach versus surgical resection after chemoradiotherapy for patients with rectal cancer (the OnCoRe project): a propensity-score matched cohort analysis. Lancet Oncol 2016;17:174-83.

136 Ackland GL, Iqbal S, Paredes LG, et al. Individualised oxygen delivery targeted haemodynamic therapy in high-risk surgical patients: a multicentre, randomised, double-blind, controlled, mechanistic trial. Lancet Respir Med 2015;3:33-41.

137 O'Connor ME, Kirwan CJ, Pearse RM, et al. Incidence and associations of acute kidney injury after major abdominal surgery. Intensive Care Med 2016:42:521-30.

138 Sievers CK, Kratz JD, Zurbriggen LD, et al. The multidisciplinary management of colorectal cancer: present and future paradigms. Clin Colon Rectal Surg 2016:29:232-8

139 Albert MR, Atallah SB, deBeche-Adams TC, et al. Transanal minimally invasive surgery (TAMIS) for local excision of benign neoplasms and early-stage rectal cancer: efficacy and outcomes in the first 50 patients. Dis Colon Rectum 2013;56:301-7.

140 Andratschke NH, Nieder C, Heppt F, et al. Stereotactic radiation therapy for liver metastases: factors affecting local control and survival. Radiat Oncol 2015;10:69. 
141 Palma S, Zwenger AO, Croce MV, et al. From molecular biology to clinical trials: toward personalized colorectal cancer therapy. Clin Colorectal Cancer 2016;15:104-15.

142 Moris D, Pawlik TM. Personalized treatment in patients with colorectal liver metastases. J Surg Res 2017;216:26-9.

143 Sharma RA, Plummer R, Stock JK, et al. Clinical development of new drugradiotherapy combinations. Nat Rev Clin Oncol 2016;13:627-42.

144 McCulloch P, Altman DG, Campbell WB, et al. No surgical innovation without evaluation: the IDEAL recommendations. Lancet 2009;374:1105-12.

145 Cancer Research UK. Bowel cancer incidence statistics. http://www. cancerresearchuk.org/health-professional/cancer-statistics/statistics-by-cancer-type/ bowel-cancer/incidence\#heading Three (accessed 08 Sep 2017).

146 National Cancer Institute. Drugs approved for colon and rectal cancer. https://www. cancer.gov/about-cancer/treatment/drugs/colorectal (accessed 08 Sep 2017).

147 Garon EB, Rizvi NA, Hui R, et al. Pembrolizumab for the treatment of non-small-cell lung cancer. N Engl J Med 2015;372:2018-28.

148 Robert C, Thomas L, Bondarenko I, et al. Ipilimumab plus dacarbazine for previously untreated metastatic melanoma. N Engl J Med 2011;364:2517-26.

149 Larkin J, Chiarion-Sileni V, Gonzalez R, et al. Combined nivolumab and ipilimumab or monotherapy in untreated melanoma. N Engl J Med 2015;373:23-34.

150 Overman MJ, McDermott R, Leach JL, et al. Nivolumab in patients with metastatic DNA mismatch repair-deficient or microsatellite instability-high colorectal cancer (CheckMate 142): an open-label, multicentre, phase 2 study. Lancet Oncol 2017:18:1182-91.

151 Rentsch M, Schiergens T, Khandoga A, et al. Surgery for colorectal cancer - trends, developments, and future perspectives. Visc Med 2016;32:184-91.

152 Mirnezami R, Moran BJ, Harvey K, et al. Cytoreductive surgery and intraperitoneal chemotherapy for colorectal peritoneal metastases. World J Gastroenterol 2014;20:14018-32

153 Lee DJ, Sagar PM, Sadadcharam G, et al. Advances in surgical management for locally recurrent rectal cancer: How far have we come? World I Gastroenterol 2017;23:4170-80.

154 van Dam RM, Wong-Lun-Hing EM, van Breukelen GJ, et al. Open versus laparoscopic left lateral hepatic sectionectomy within an enhanced recovery ERAS $®$ programme (ORANGE II-trial): study protocol for a randomised controlled trial. Trials 2012;13:54

155 ISRCTN registry. LAVA: Liver resection surgery versus thermal ablation for colorecta liver metastases. http://www.isrctn.com/ISRCTN52040363 (accessed 08 Sep 2017)

156 U.S National Library of Medicine. Chemotherapy and Maximal Tumor Debulking of Multi-organ Colorectal Cancer Metastases (ORCHESTRA). https://clinicaltrials.gov/ ct2/show/NCT01792934 (accessed 08 Sep 2017).

157 Lawler M, Kaplan R, Wilson RH, et al. Changing the paradigm — multistage multiarm randomized trials and stratified cancer medicine. Oncologist 2015;20:849-51.

158 Cho M, Carter J, Harari S, et al. The interrelationships of the gut microbiome and inflammation in colorectal carcinogenesis. Clin Lab Med 2014;34:699-710.

159 Zeuner A, Todaro M, Stassi G, et al. Colorectal cancer stem cells: from the crypt to the clinic. Cell Stem Cell 2014;15:692-705.

160 McGranahan N, Furness AJ, Rosenthal R, et al. Clonal neoantigens elicit T cell immunoreactivity and sensitivity to immune checkpoint blockade. Science 2016:351:1463-9.

161 Le DT, Durham JN, Smith KN, et al. Mismatch repair deficiency predicts response of solid tumors to PD-1 blockade. Science 2017:357:409-13.

162 Galon J, Costes A, Sanchez-Cabo F, et al. Type, density, and location of immune cells within human colorectal tumors predict clinical outcome. Science 2006:313:1960-4

163 Wang $X$, Yang Y, Huycke MM. Microbiome-driven carcinogenesis in colorectal cancer: models and mechanisms. Free Radic Biol Med 2017;105:3-15.

164 Whistance RN, Conroy T, Chie W, et al. European organisation for the research and treatment of cancer quality of life group. clinical and psychometric validation of the EORTC QLQ-CR29 questionnaire module to assess health-related quality of life in patients with colorectal cancer. Eur J Cancer 2009;45:3017-26.

165 Cherny NI, Sullivan R, Dafni U, et al. A standardised, generic, validated approach to stratify the magnitude of clinical benefit that can be anticipated from anti-cancer therapies: the european society for medical oncology magnitude of clinical benefit scale (ESMO-MCBS). Ann Oncol 2015:26:1547-73.

166 Wong CK, Guo VY, Chen J, et al. Methodological and reporting quality of comparative studies evaluating health-related quality of life of colorectal cancer patients and controls: a systematic review. Dis Colon Rectum 2016;59:1073-86.

167 Quidde J, Hegewisch-Becker S, Graeven U, et al. Quality of life assessment in patients with metastatic colorectal cancer receiving maintenance therapy after firstline induction treatment: a preplanned analysis of the phase III AIO KRK 0207 trial. Ann Oncol 2016;27:2203-10.

168 Bours MJ, van der Linden BW, Winkels RM, et al. Candidate predictors of healthrelated quality of life of colorectal cancer survivors: a systematic review. Oncologist 2016:21:433-52

169 Bryant CL, Lunniss PJ, Knowles CH, et al. Anterior resection syndrome. Lancet Oncol 2012;13:e403-8

170 Andreyev J. Gastrointestinal symptoms after pelvic radiotherapy: a new understanding to improve management of symptomatic patients. Lancet Oncol 2007;8:1007-17.
171 Battersby NJ, Juul T, Christensen P, et al. Predicting the risk of bowel-related quality-of-life impairment after restorative resection for rectal cancer: a multicenter cross-sectional study. Dis Colon Rectum 2016;59:270-80.

172 Scheer AS, Boushey RP, Liang S, et al. The long-term gastrointestinal functional outcomes following curative anterior resection in adults with rectal cancer: a systematic review and meta-analysis. Dis Colon Rectum 2011;54:1589-97.

173 Birgisson H, Påhlman L, Gunnarsson U, et al. Late adverse effects of radiation therapy for rectal cancer - a systematic overview. Acta Oncol 2007:46:504-16.

174 Maris A, Devreese AM, D’Hoore A, et al. Treatment options to improve anorectal function following rectal resection: a systematic review. Colorectal Dis 2013:15:e67-78.

175 Lin KY, Granger CL, Denehy L, et al. Pelvic floor muscle training for bowel dysfunction following colorectal cancer surgery: a systematic review. Neurourol Urodyn 2015;34:703-12.

176 Visser WS, Te Riele WW, Boerma D, et al. Pelvic floor rehabilitation to improve functional outcome after a low anterior resection: a systematic review. Ann Coloproctol 2014:30:109-14.

177 Glover M, Smerdon GR, Andreyev HJ, et al. Hyperbaric oxygen for patients with chronic bowel dysfunction after pelvic radiotherapy (HOT2): a randomised, doubleblind, sham-controlled phase 3 trial. Lancet Oncol 2016;17:224-33.

178 Andreyev HJ, Benton BE, Lalji A, et al. Algorithm-based management of patients with gastrointestinal symptoms in patients after pelvic radiation treatment (ORBIT): a randomised controlled trial. Lancet 2013;382:2084-92

179 Andreyev HJ, Muls AC, Norton C, et al. Guidance: The practical management of the gastrointestinal symptoms of pelvic radiation disease. Frontline Gastroenterol 2015;6:53-72.

180 Rodriguez JL, Hawkins NA, Berkowitz Z, et al. Factors associated with healthrelated quality of life among colorectal cancer survivors. Am J Prev Med 2015;49:S518-S527.

181 Demark-Wahnefried W, Rogers LQ, Alfano CM, et al. Practical clinical interventions for diet, physical activity, and weight control in cancer survivors. CA Cancer J Clin 2015;65:167-89.

182 Wu W, Guo F, Ye J, et al. Pre- and post-diagnosis physical activity is associated with survival benefits of colorectal cancer patients: a systematic review and meta-analysis. Oncotarget 2016:7:52095-103.

183 Soares-Miranda L, Abreu S, Silva M, et al. Cancer survivor study (CASUS) on colorectal patients: longitudinal study on physical activity, fitness, nutrition, and its influences on quality of life, disease recurrence, and survival. Rationale and design. Int J Colorectal Dis 2017:32:75-81.

184 Alfano CM, Bluethmann SM, Tesauro G, et al. NCl funding trends and priorities in physical activity and energy balance research among cancer survivors. J Nat/ Cancer Inst 2016:108.

185 Blanch-Hartigan D, Forsythe LP, Alfano CM, et al. Provision and discussion of survivorship care plans among cancer survivors: results of a nationally representative survey of oncologists and primary care physicians. J Clin Oncol 2014;32:1578-85.

186 Numico G, Pinto C, Gori S, et al. Clinical and organizational issues in the management of surviving breast and colorectal cancer patients: attitudes and feelings of medical oncologists. PLoS One 2014:9:e101170.

187 de Lorenzo F, Haylock P. Preface. Cancer 2013;119(Suppl 11):2089-93.

188 Richards M, Corner J, Maher J. The National Cancer Survivorship Initiative: new and emerging evidence on the ongoing needs of cancer survivors. Br J Cancer 2011:105(Suppl 1):S1-4

189 Macmillan Cancer Support. Care after Cancer. http://www.macmillan.org.uk/ documents/getinvolved/campaigns/campaigns/survivorship/survivorshipreport2009. pdf (accessed 08 Sep 2017).

190 El-Shami K, Oeffinger KC, Erb NL, et al. American cancer society colorectal cancer survivorship care guidelines. CA Cancer J Clin 2015;65:427-55.

191 Global Alliance for Genomics and Health. Enabling genomic data sharing for the benefit of human health. https://genomicsandhealth.org/ (accessed 08 Sep 2017).

192 Siu LL, Lawler M, Haussler D, et al. Facilitating a culture of responsible and effective sharing of cancer genome data. Nat Med 2016;22:464-71.

193 Lawler M, Haussler D, Siu LL, et al. Sharing clinical and genomic data on cancer the need for global solutions. N Eng/ J Med 2017:376:2006-9.

194 McArt DG, Blayney JK, Boyle DP, et al. PICan: An integromics framework for dynamic cancer biomarker discovery. Mol Oncol 2015;9:1234-40.

195 Tannock IF, Hickman JA. Limits to precision cancer medicine. N Eng/ J Med 2017;376:96-7

196 Power E, Simon A, Juszczyk D, et al. Assessing awareness of colorectal cancer symptoms: measure development and results from a population survey in the UK. BMC Cancer 2011:11:366.

197 Keighley MR, O'Morain C, Giacosa A, et al. Public awareness of risk factors and screening for colorectal cancer in Europe. Eur J Cancer Prev 2004:13:257-62.

198 Gray SW, Armstrong K, Demichele A, et al. Colon cancer patient information seeking and the adoption of targeted therapy for on-label and off-label indications. Cancer 2009:115:1424-34.

199 Brown S, Greenfield D, Thompson J. Knowledge and awareness of long-term and late treatment consequences amongst colorectal cancer survivors: a qualitative study. Eur J Oncol Nurs 2016;20:191-8. 
200 Craig P, Dieppe P, Macintyre S, et al. Developing and evaluating complex interventions: the new medical research council guidance. BMJ 2008;337:a1655

201 Moore GF, Audrey S, Barker M, et al. Process evaluation of complex interventions: medical research council guidance. BMJ 2015;350:h1258.

202 Cancer Research UK. Understanding gpattitudes to cancerpreventing drugs. http://www.cancerresearchuk.org/sites/default/files/understanding_gp attitudes_to_cancer_preventing_drugs_full_evidence_report.pdf (accessed 08 Sep 2017).

203 Glaser AW, Fraser LK, Corner J, et al. Patient-reported outcomes of cancer survivors in england 1-5 years after diagnosis: a cross-sectional survey. BMJ Open 2013;3:e002317
204 McNair AG, Whistance RN, Forsythe RO, et al. Synthesis and summary of patientreported outcome measures to inform the development of a core outcome set in colorectal cancer surgery. Colorectal Dis 2015;17:0217-229.

205 Lawler M, Le Chevalier T, et al. European Cancer Concord (ECC). Lancet Oncol 2014;15:258-60.

206 Kehl KL, Arora NK, Schrag D, et al. Discussions about clinical trials among patients with newly diagnosed lung and colorectal cancer. J Natl Cancer Inst 2014;106 pii: dju216.

207 Ciardiello F, Adams R, Tabernero J, et al. Awareness, understanding, and adoption of precision medicine to deliver personalized treatment for patients with cancer: a multinational survey comparison of physicians and patients. Oncologist 2016;21:292-300. 